Portland State University

PDXScholar

$1-2009$

\title{
Application of LRFD Geotechnical Principles for Pile Supported Bridges in Oregon: Phase 1
}

Trevor D. Smith

Portland State University

Peter Dusicka

Portland State University

Follow this and additional works at: https://pdxscholar.library.pdx.edu/trec_reports

Part of the Civil and Environmental Engineering Commons, and the Transportation Commons Let us know how access to this document benefits you.

\section{Recommended Citation}

Smith, Trevor, and Peter Dusicka. Application of LRFD Geotechnical Principles for Pile Supported Bridges in Oregon: Phase 1. OTREC-TT-09-01. Portland, OR: Transportation Research and Education Center (TREC), 2009. https://doi.org/10.15760/trec.98

This Report is brought to you for free and open access. It has been accepted for inclusion in TREC Final Reports by an authorized administrator of PDXScholar. Please contact us if we can make this document more accessible: pdxscholar@pdx.edu. 

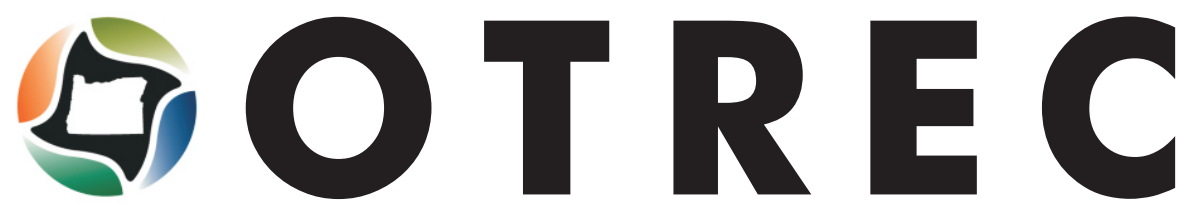

TRANSPORTATION

FINAL REPORT

EDUCATION CONSORTIUM

\section{Application of LRFD \\ Geotechnical Principles for Pile Supported Bridges in Oregon: Phase 1}

OTREC-TT-09-01 January 2009 


\title{
APPLICATION OF LRFD GEOTECHNICAL PRINCIPLES FOR PILE SUPPORTED BRIDGES IN OREGON: PHASE 1
}

\section{Final Report}

\author{
OTREC-TT-09-01 \\ by \\ Trevor D. Smith \\ Peter Dusicka \\ Portland State University
}

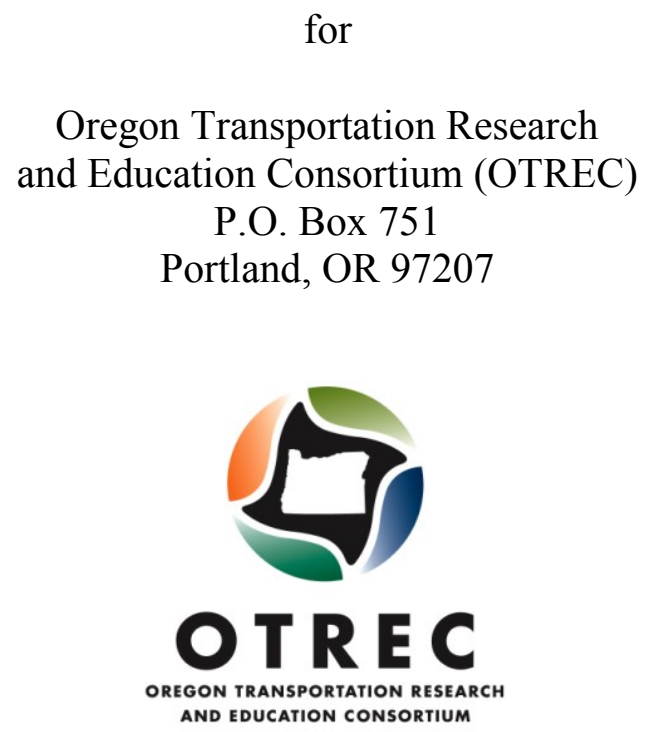

January 2009 



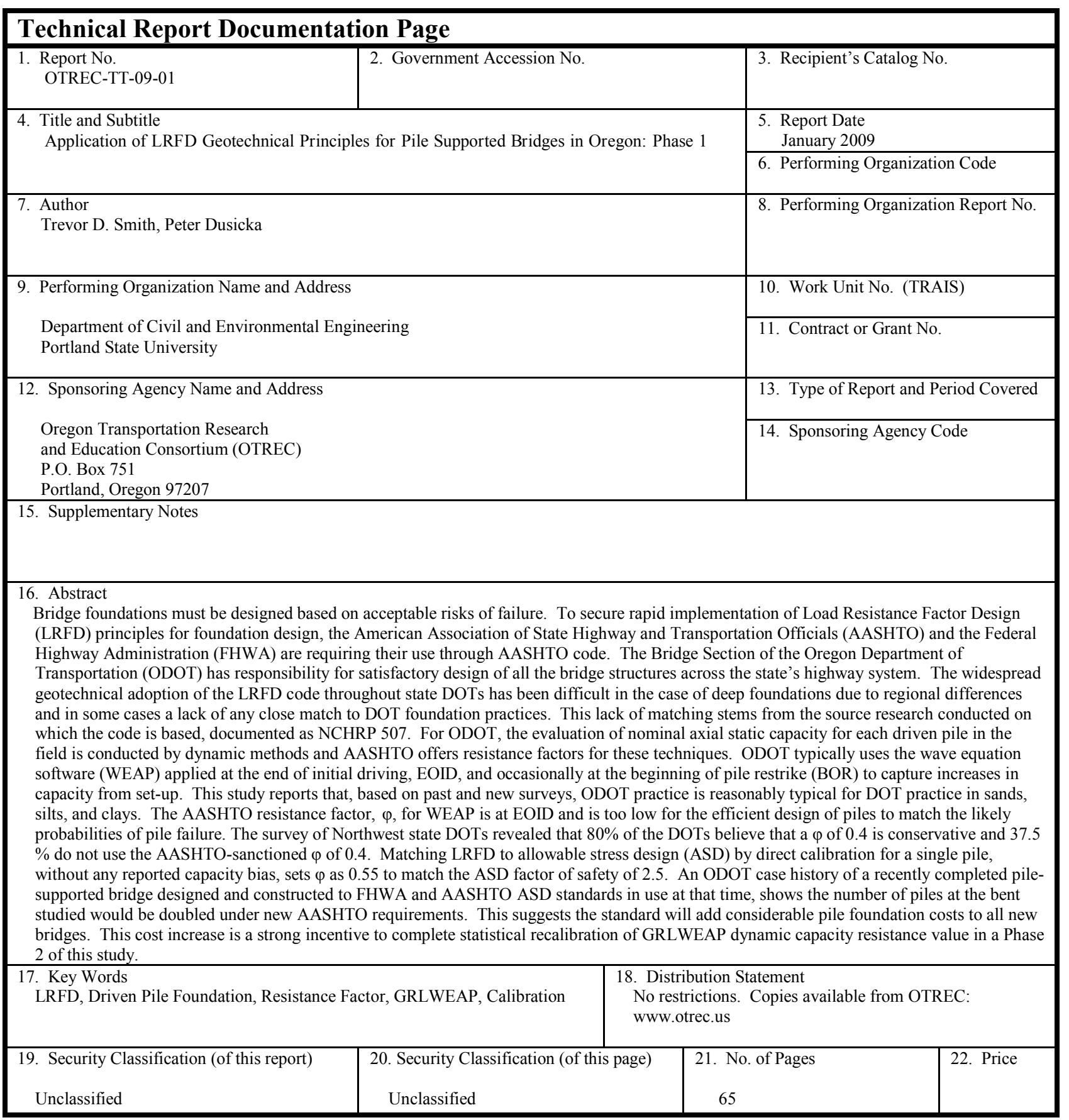




\section{ACKNOWLEDGEMENTS}

The authors would like to thank Mr. Jan Six of the Oregon Department of Transportation, Bridge Section, Mr. Richard Barrows and Ms. Diann Morehouse of FHWA Western Federal Lands, Vancouver, and Mr. Tony Allen of the Washington State Department of Transportation for their assistance in this research. This project was funded by the Oregon Transportation Research and Education Consortium (OTREC), Oregon Department of Transportation, Bridge Section, Salem; the Oregon Department of Transportation, Region 1 Geo-Hydro Section; and.

\section{DISCLAIMER}

The contents of this report reflect the views of the authors, who are solely responsible for the facts and the accuracy of the material and information presented herein. This document is disseminated under the sponsorship of the U.S. Department of Transportation University Transportation Centers Program and the Oregon Department of Transportation in the interest of information exchange. The U.S. Government and Oregon Department of Transportation assume no liability for the contents or use thereof. The contents do not necessarily reflect the official views of the U.S. Government and Oregon Department of Transportation. This report does not constitute a standard, specification, or regulation. 


\section{TABLE OF CONTENTS}

TABLE OF CONTENTS ……................................................................................................. APPENDICES ERROR! BOOKMARK NOT DEFINED.

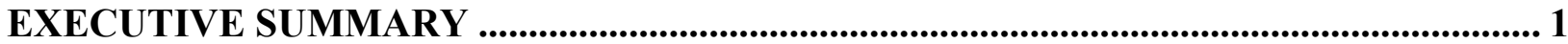

1.0 PROBLEM STATEMENT AND STUDY OBJECTIVES.......................................... 3

1.1 FEDERAL NEEDS AND AASHTO DIRECTIVES …….......................................... 3

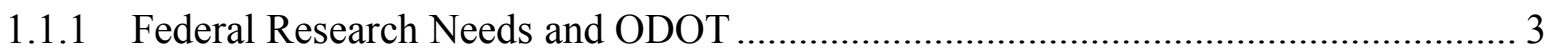

1.1.2 Problem Statement and Background.................................................................. 4

1.2 TECHNOLOGY TRANSFER IMPLEMENTATION OBJECTIVES ………….............. 6

1.3 GEOTECHNICAL UNCERTAINTY AND SITE VARIABILITY ………………........... 7

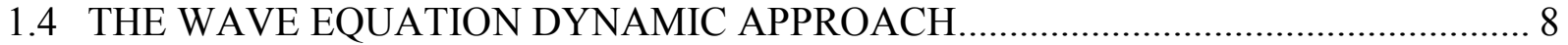

2.0 IMPLEMENTATION ISSUES FOR OREGON ……...................................................... 11

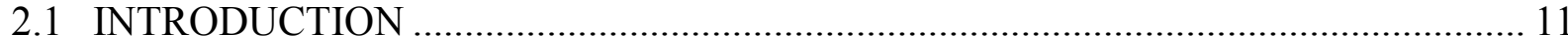

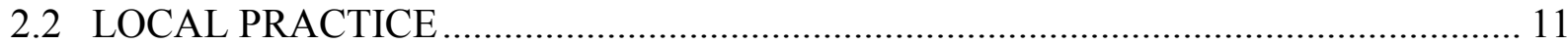

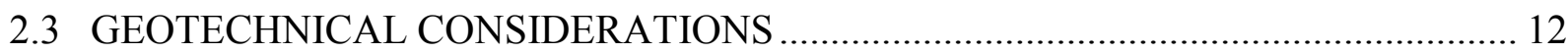

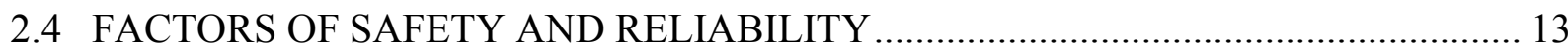

3.0 PRACTITIONER SURVEYS.................................................................................. 17

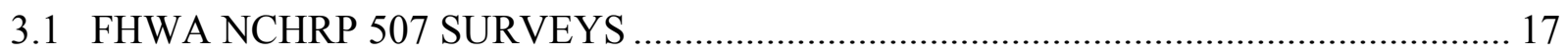

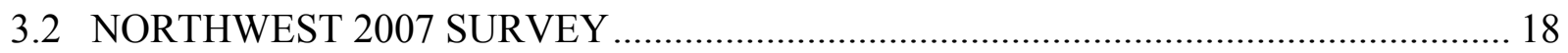

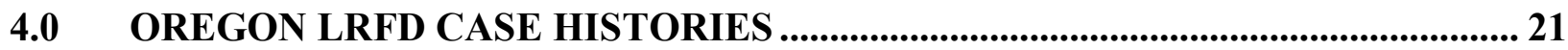

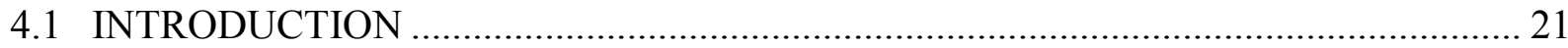

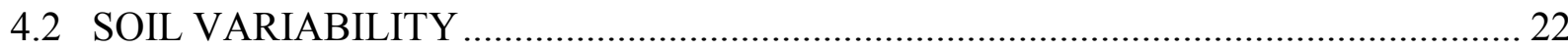

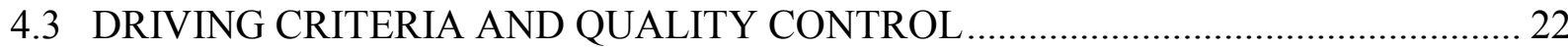

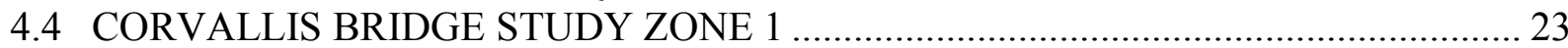

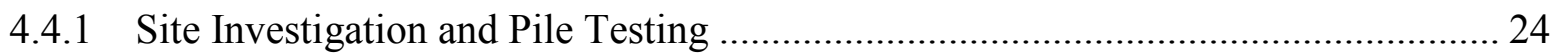

4.4.1 GRLWEAP Bearing Graph and CAPWAP Nominal Capacities ............................ 24

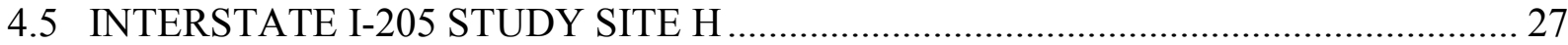

4.5.1 Site Investigation and Pile Testing ……………………………………….... 28

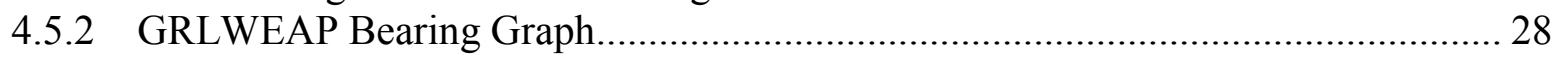

5.0 AVAILABLE DATABASES........................................................................................... 31

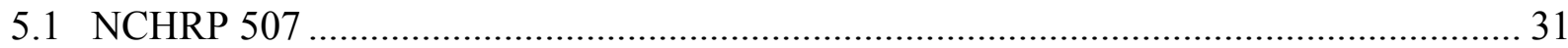

5.2 WSDOT ROLE AND PHASE 2 DATABASE STATUS ………................................ 32

6.0 CONCLUSIONS AND PHASE 2 RECOMMENDATIONS ........................................ 35

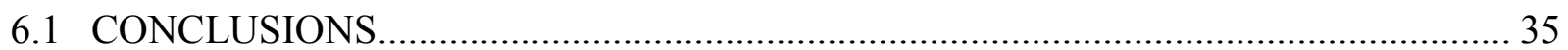

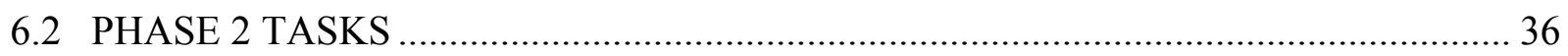

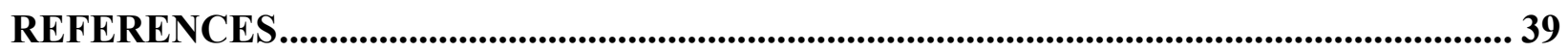

APPENDICES

APPENDIX A SURVEY RESULTS

APPENDIX B COMMENTS ON SURVEY 


\section{APPENDIX C DISCUSSION IN GROUP DISCUSSION}

\section{LIST OF TABLES}

Table 2.1: GRLWEAP Resistance Factors by Fitting to ASD for Strength I........................... 15

Table 4.1: GRLWEAP and CAPWAP Determined Number of Piles at Bent 3 ........................ 26

\section{LIST OF FIGURES}

Figure 1.1: Example of GRLWEAP Bearing Graph ......................................................... 8

Figure 4.1: Bearing Graph: Corvallis, Zone 1 Bent 3 TP-1 .............................................. 25

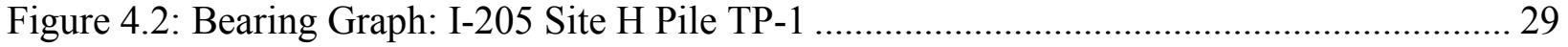




\section{ABBREVIATIONS AND ACRONYMS}

\begin{tabular}{|c|c|}
\hline $\begin{array}{l}\text { AASHTO } \\
\text { ASD }\end{array}$ & $\begin{array}{l}\text { American Association of State Highway and Transportation Officials } \\
\text { allowable stress desion }\end{array}$ \\
\hline $\begin{array}{l}\text { ASD } \\
\mathrm{POD}\end{array}$ & allowable stress design \\
\hline BOR & beginning of restrike \\
\hline CAPWAP & CAse Pile Wave Analysis Program \\
\hline CD & consolidated drained \\
\hline $\mathrm{COV}$ & coefficient of variation \\
\hline CPT & Cone Penetration Test \\
\hline $\mathrm{CU}$ & consolidated undrained \\
\hline DFLTD & Deep Foundation Load Test Database \\
\hline DL & dead load \\
\hline DOT & department of transportation \\
\hline EOID & end of initial driving \\
\hline EOR & end of restrike \\
\hline FHWA & Federal Highway Administration \\
\hline GRLWEAP & Goble Rausche Likins Wave Equation Analysis of Piles \\
\hline LFRD & Load Resistance Factor Design \\
\hline LL & live load \\
\hline NCHRP & National Cooperative Highway Research Program \\
\hline ODOT & Oregon Department of Transportation \\
\hline PDA & pile driving analyzer \\
\hline RD\&T & Research, Development and Technology \\
\hline SPT & Standard Penetration Test \\
\hline UU & unconsolidated undrained \\
\hline WSDOT & Washington State Department of Transportation \\
\hline
\end{tabular}




\section{EXECUTIVE SUMMARY}

Bridge foundations must be designed based on acceptable risks of failure. To secure rapid implementation of Load Resistance Factor Design (LRFD) reliability-based principles, the American Association of State Highway and Transportation Officials (AASHTO) and the Federal Highway Administration (FHWA) are requiring their use through the AASHTO bridge design code. This code creates a precedent in the areas of geotechnical policy, implementation to fit highly regionalized "standards of practice", and dissemination of knowledge. The Bridge Section of the Oregon Department of Transportation (ODOT) is responsible for satisfactory design of all the bridge structures within the state's highway system. In addition, the Bridge Section plays a significant leadership role in the distribution and implementation of new and emerging bridge technologies.

The widespread geotechnical adoption by the nation's departments of transportation (DOTs) of LRFD principles specified in the AASHTO code has been difficult in the case of deep foundations. LRFD principles for driven pile design, including resistance reduction factors (called $\varphi$ resistance factors) for dynamic methods, appeared recently in the third edition of the AASHTO Bridge Design Specifications (AASHTO 2004). Implementation concerns caused major revisions to the AASHTO code, and a fourth edition was subsequently released (AASHTO 2007). Both editions drew heavily from the comprehensive work performed for both drilled shafts and driven pile foundations by the National Cooperative Highway Research Program (Paikowsky et al. 2004), issued in the report referred to as NCHRP 507. Surveys by FHWA in 1997 and 1999 helped capture the various DOTs' practice for pile design and load capacity verification across the nation, providing knowledge of actual LRFD use, frequency of load tests, and pile driving data including restrike.

Pile capacity, whether measured by static analyses, dynamic methods, or full-scale load test methods, is governed partly by the soil layer(s) shear strength existing along the pile length and partly by soil conditions at the pile tip. Typically, geotechnical sampling, testing, and logging of boreholes are limited due to time and economic constraints. As LRFD implementation continues, the outsourced geotechnical baseline site investigation information will need to reflect the needs of reliability-based design. The confirmation of nominal capacity for each pile in the field is often conducted by dynamic methods, using measurements of pile penetration and/or input energy at each hammer blow. The well-known GRLWEAP software (Pile Dynamics Inc. 2005) calculates the induced stress and displacement waves traveling along the pile for a single hammer blow. Based on survey results, there is strong opinion among DOT practitioners that supports increasing the AASHTO-reported GRLWEAP resistance factors, $\varphi$, in the code when used on restrike to capture pile capacity increases after initial driving.

In the most recent version, GRLWEAP features include improved set-up models, as well as use of the pile static capacity DRIVEN software code (Mathias and Cribbs 1998) for soil resistance distribution. Close examination of NCHRP 507, which forms the basis of much of the deep foundation sections of the AASHTO fourth edition code, reveals some reliance on local 
judgment and experience in field verification to establish factored nominal resistance. As part of this Phase 1 research effort for ODOT, a survey of Northwest state DOT current pile design practice relating to LRFD was conducted in August 2007, and reported by FHWA's Western Federal Lands Highway Division. The survey's objective was to assess both the overall use of GRLWEAP in Northwest practice and the effects of applying the AASHTO resistance factors using GRLWEAP to bridge designs in the Northwest.

FHWA has been collecting deep foundation load test information and has compiled a database up to 2004. The information collected includes load test results, soil boring logs, laboratory data, and field tests for both driven and drilled shaft deep foundations. The database also includes pile driving logs up to the end of initial driving (EOID), as well as the restrike driving log when a pile is re-driven after some delay, referred to as beginning of restrike (BOR). This Phase 1 study revealed that considerable information was missing for approximately two-thirds of the NCHRP 507 pile load test database on restrike. This database offers more than 1,000 load test entries from 1985 to 2004 and has been obtained by the research group in preparation for a Phase 2 recalibration study. ODOT has obtained the NCHRP 507 database with modifications, including quality metrics and pile selection strategy from the Washington State Department of Transportation following its AASHTO resistance factor recalibration.

J. Long (Long 2002) accessed seven independent databases to identify statistical means and standard deviations for seven capacity predictive methods. Some of these databases included EOID and BOR driving data that permit examination of the GRLWEAP produced bearing graph, as well as CAse Pile Wave Analysis Program (CAPWAP) predictions of nominal capacity. For both these methods, Long illustrated the improvement in predictive ability achieved by moving from EOID to BOR blow counts, something NCHRP 507 did not illustrate for the GRLWEAP bearing graph. The improvement in both means and standard deviations reported by Long when comparing EOID to BOR is statistically better for GRLWEAP than for CAPWAP.

As part of this study, a case history examination of an ODOT bridge constructed in 1990 showed that strict interpretation of the AASHTO requirements at EOID would have required more than double the number of piles which were actually installed at the Bent 3 study site. With Northwest state DOTs projecting construction of approximately 750 new bridges in the next 10 years, implementation of LRFD by AASHTO code will likely increase foundation costs considerably. In summary this study reports that allowable stress design (ASD) calibration to LRFD, Northwest practice, and the ODOT case study all support the preliminary increase of AASHTO's GRLWEAP resistance factor from 0.4 to a range between 0.5 and 0.55 . A discussion of the likely tasks to be completed for statistical justification of a full recalibration is also presented. For any transition period, during which a complete statistical analysis of GRLWEAP at EOID and BOR conditions is conducted, a $\varphi$ resistance factor of 0.5 is recommended. 


\subsection{PROBLEM STATEMENT AND STUDY OBJECTIVES}

\subsection{FEDERAL NEEDS AND AASHTO DIRECTIVES}

\subsubsection{Federal Research Needs and ODOT}

The efficient and safe transportation of people and goods all employ a variety of bridge structures irrespective of the particular travel mode: road, rail, and air. The Research, Development and Technology (RD\&T) plan (Lacombe et al. 2004) states that 28 percent of the approximately 600,000 large bridges in the United States are substandard. This means vehicles cross deficient structures more than 1 billion times each day. Within the Federal Highway Administration (FHWA) section of the RD\&T plan, there are reports of research needs from their three key structures research groups, given in italics below. These groups, their research needs, and the extracted connections to this study are summarized below:

- The Bridge of the Future - foundation performance is part of the "total systems" approach.

- Stewardship and Management for the Future - load testing and Load Resistance Factor Design (LRFD) risk-based implementation of state-of-the-art for bridge life cycle determination.

- Safety, Reliability, and Security of Bridges - natural hazard loadings (flood, earthquake, and wind) call for a multidisciplinary approach, especially seismic earthquake response.

The Federal Lands Technology Group portion of the RD\&T report directs investments in material behavior of bridge structures, as well as implementing software and design principles to achieve a better understanding of structural designs. Advances in the reliability and risk performance of the superstructure elements, concrete and steel, are well ahead of design practice relating to substructure geotechnical risk principles. Geotechnical and structural disciplines are the two technical areas for which FHWA has documented past communication issues (DiMaggio et al. 1999). In part, these issues relate to aligning structural and geotechnical design principles for axial capacity under LRFD.

The Bridge Section of the Oregon Department of Transportation (ODOT) is responsible for satisfactory design and analysis of all the bridge structures in the state's highway system. In addition, it provides significant leadership in the distribution and implementation of new and emerging bridge technologies. LRFD methods for structural bridge elements have been used for many years in ODOT and are well accepted by structural design engineers. These methods are well established through nationally recognized codes of practice for structural materials. In order to design bridges that fully comply with the required reliability performance standards, foundation engineers must also design bridge foundations based on "acceptable" risks of failure. 
To secure rapid implementation of LRFD principles, developed by structural engineers, the American Association of State Highway and Transportation Officials (AASHTO) and FHWA now require adoption by each department of transportation (DOT) of these principles as detailed in the AASHTO LFRD Bridge Designs Specifications code. This code creates a precedent in the areas of geotechnical design policy, implementation to fit highly regionalized "standards of practice" across the nation, and the dissemination of centralized knowledge. The widespread geotechnical adoption of the LRFD code by DOTs has been difficult in the case of deep foundations. The regional implementation of LRFD principles from the AASHTO code in ODOT practice for driven piles is the subject of this report.

\subsubsection{Problem Statement and Background}

The LRFD methodology at the ultimate limit state calls for the load to be factored up by load factors $(\gamma)$ assigned to the load source (e.g., dead, live, wind) and compared to a reduced nominal resistance, $R_{n k}$, employing resistance factors $(\varphi)$. The inequality to be satisfied in LRFD-based design is set out in the equation below:

$$
\sum \gamma_{\mathrm{ij}} \mathbf{Q}_{\mathrm{ij}} \leq \boldsymbol{\varphi}_{\mathrm{k}} \mathbf{R}_{\mathbf{n k}}
$$

Where: $\quad \mathrm{Q}_{\mathrm{ij}}=$ Structural load from each source condition

$\gamma_{\mathrm{ij}}=$ Magnification load factor set by the code

$\mathrm{R}_{\mathrm{nk}}=$ Nominal strength-based resistance established by a defined method

$\varphi_{\mathrm{k}}=$ Declared resistance factor for the defined resistance method

$Q_{i j}$ and $R_{n k}$ are not deterministic but are continuous variables; therefore, the calibration of $\gamma_{i j}$ and $\varphi_{\mathrm{k}}$ to foundation design is statistically determined to arrive at a fixed Reliability Index value, $\beta$, quantifying risk for the foundation. It has been accepted that driven piles with high redundancy in a pile group are permitted to have $1 / 100$ probability of "failure," which sets $\beta$ at 2.3 as the target. Low redundancy pile groups ( $\leq 4$ piles) require a stricter $1 / 1000$ probability of exceedance; thus, $\beta$ at 3 is the target reliability. It should be recognized that the appropriate resistance value (determined by any method) to satisfy the inequality of Equation (1-1) is a function of the structure's proportion of live load (LL) and dead load (DL) and the code that sets the $\gamma_{\mathrm{ij}}$ factors (see Section 2.4).

The LRFD approach can be compared to the popular and widely used Allowable Stress Design (ASD) method, which requires the use of a global factor of safety, $F$, to arrive at a safe maximum pile design capacity according to the following equation:

$$
\mathbf{R}_{\text {des }}=\frac{\mathbf{R}_{\text {ult }}}{\mathbf{F}}
$$

Where:

$$
\mathrm{R}_{\text {des }}=\quad \text { Safe design capacity }
$$




$$
\begin{array}{lll}
\mathrm{R}_{\mathrm{ult}} & = & \text { Ultimate capacity } \\
\mathrm{F} & = & \text { Factor of safety }
\end{array}
$$

The appropriate value of $\mathrm{F}$ takes into consideration such factors as uncertainty in soil properties and loading conditions, and also the degree of pile construction control in the case of pile dynamic capacity methods. Calibration for LRFD $\varphi_{\mathrm{k}}$ by matching to ASD can be performed taking the ultimate capacity $\mathrm{R}_{\mathrm{ult}}$ equal to the nominal strength $\mathrm{R}_{\mathrm{nk}}$, and is briefly explored in Chapter 2 of this report.

Given the mandated implementation date for adoption of the AASHTO bridge code of October 1, 2007, the number of individual state DOTs making efforts to implement the code with load modifications has increased. Continued research efforts to meet local needs as well as bridge code changes are occurring. The concerns of state foundation engineering practitioners caused major revisions to the code, resulting in the subsequent release of a fourth edition of the code (AASHTO 2007). In parallel to the AASHTO/FHWA effort, the last 5 years have seen a growth in LRFD research material published in foundation engineering journals and conference proceedings. It is evident that LFRD implementation is proceeding, but slowly. Better recognition of regional and local standards of practice, together with improvements in statistical competency to assist local implementation of the AASHTO recommendations, is beginning to gain momentum.

The most recent edition of the AASHTO bridge design code (2007) draws heavily on the comprehensive work performed for both drilled shafts and driven pile foundations by the National Cooperative Highway Research Program (Paikowsky et al. 2004), referred to hereafter as the NCHRP 507 report. The NCHRP 507 work statistically established national requirements for $\varphi$ resistance factors by setting dead load to live load ratios, site variability, pile redundancy, soil types, and the quality of dynamic testing - all of which are, in fact, regional factors. The AASHTO code is an attempt to secure uniform implementation of LRFD. In addition, a series of significant publications has been issued by FHWA, the Transportation Research Board, and the National Highway Institute. New editions of standard foundation engineering reference works increasingly introduce LRFD principles, but with some differences, e.g. The Engineering of Foundations (Salgado 2008). In some instances, such as the definition of soil properties for nominal capacity values, there are disagreements with the AASHTO code that will likely handicap LRFD implementation. A clear presentation of axial capacity, load, and $\varphi$ resistance factor historical development, as well as the difficulties relating to driven pile foundations, has been provided by T. Allen (Allen 2005a). In addition, a thorough localized recalibration of the $\varphi$ resistance factor was undertaken by the Washington State Department of Transportation (WSDOT) (Allen 2005b) for the Modified Gates pile driving formulae based on reinterpretation of the same pile driving databases accessed by NCHRP 507. Some geotechnical observations pertaining to these past efforts and their relevance to ODOT are presented in Chapter 5.

The updated "Design and Construction of Driven Pile Foundations" (Hannigan et al. 2006) is the most recent and widespread FHWA effort, and it remains the principal guide for pile design used by both public and private sector practitioners. This two-volume report offers a comprehensive exploration of pile design and analysis in Volume I, and of field testing quality control and field dynamic testing in Volume II. The key communication connections to the 
structural engineer, bridge engineer, and contractor are well presented, as are the decisions concerning construction capacity verification testing. Both volumes are directed toward ASD, and they do not incorporate LRFD principles. A simple example is presented in Appendix G of Volume I, following discussion of the LRFD structural origins. However, the LRFD combined reliability approach, using the static analysis factor method multiplied by the field verification technique factor, presented in Appendix G of Volume I, has now been discredited (Allen 2005a) and removed from the LRFD bridge design code by AASHTO.

\subsection{TECHNOLOGY TRANSFER IMPLEMENTATION OBJECTIVES}

The reality is that piles are often driven at locations for which no borehole exists at that position to provide concise subsurface conditions. Subsurface conditions, together with pile size and type, dictate the axial capacity. This reality limits the direct application and reliability of static methods derived from borehole testing of samples to those physical locations coinciding with borehole locations. This is unfortunate as the NCHRP 507 study illustrates that static methods are comparable to even the best dynamic methods, and in some soil/pile combinations are actually better. In all cases, the basis for statistical comparison between different prediction methods is the static load test capacity of the pile, which is often conducted some time after driving. Davisson's interpretation of capacity from the load test result is used. However, predicting Davisson's criteria for identifying the capacity is not the intent of either the static capacity analytical methods or the dynamic methods. Thus, in addition to analytical modeling errors, a "bias" is introduced, $b_{\mathrm{R}}$, and is statistically reported from database studies.

In those cases for which a borehole does not exist at every pile location, FHWA has endorsed the establishment of a normal axial capacity, $\mathrm{R}_{\mathrm{nk}}$, from dynamic information recorded at the time of pile driving. The assumption has then been made that statistical spatial variability, systematic error, and design model error can be included by the use of large pile testing databases to establish the $\varphi$ resistance factor. However, a weakness is introduced if the number of load tests is small in a particular soil, pile type, and verification method combination. The NCHRP 507 report and the AASHTO code recommend a minimum number of field static load tests and/or dynamic tests at such a project site in order to achieve the desired reliability for that bridge's foundation.

The evaluation by ODOT of the nominal static capacity for each pile is performed in the field by dynamic methods, and the AASHTO code presents $\varphi$ resistance factors for these techniques in its LRFD methodology. The use of the Wave Equation Analysis of Pile Driving (GRLWEAP) computer program (Pile Dynamics Inc. 2005), which models the pile driving hammer, driving accessories, pile, and soil by a viscous mass-spring system, is both widespread and constitutes the industry standard internationally.

The objectives of the first phase of this study are to discuss the evolution of the $\varphi$ resistance factors, attempt to gauge the magnitude of the anticipated pile changes for ODOT, measure regional support for a procedure to gain acceptance of raising the $\varphi$ resistance factor locally when GRLWEAP is employed, report any experience of other affected states, and obtain the pile load test data required for a GRLWEAP Phase 2 recalibration. Two activities have been undertaken to build support for increasing the $\varphi$ value. First, the "state-of-practice" in Oregon as it relates to GRLWEAP experience and pile performance is documented. Second, GRLWEAP 
re-analyses of two bridge pile foundations are performed to quantify the effects of LRFD implementation in common western Oregon soils. It is anticipated that both these activities will lead to supporting preliminary revision of the $\varphi$ resistance factor for GRLWEAP capacity values at restrike to recognize the gain in capacity over time, called set-up, and the improved statistical confidence.

\subsection{GEOTECHNICAL UNCERTAINTY AND SITE VARIABILITY}

Pile capacity, whether established by static analyses, dynamic testing in the field at the time of driving, or load test methods, is governed by the soil layer(s) shear strength around the pile perimeter and at the pile tip. Because of time and economic constraints, however, only limited geotechnical sampling, testing, and logging of boreholes are performed. By assigning a higher $\varphi$ resistance factor, AASHTO declared that the pile driving analyzer (PDA) signal matching technique with CAse Pile Wave Analysis Program (CAPWAP) technology is more reliable; however, use of this technology is cost-prohibitive for many bridge piling contracts.

The AASHTO code requires a minimum number of either static load tests or PDA signal matching techniques to be conducted. To establish the appropriate $\varphi$ resistance factor from CAPWAP signal matching, consideration is given in the code to (1) the total number of piles within a given site, and (2) the variability of the site, which is assessed as Low, Medium, or High. Site variability would also be of interest in determining likely input variations of soil conditions in GRLWEAP. This variability assessment is based on the coefficient of variation (COV) of borehole soil property means used to characterize the site. Often the only property of sufficient quantity to be statistically significant is the result from the Standard Penetration Test (SPT) blow counts (which carries high uncertainty). The present code is not clear on individual site definitions, and often too few boreholes are available to establish meaningful COV values across significant layers. Site definitions are generally left to the foundation practitioner, as no guidance is provided by the FHWA in the driven pile design manual (Hannigan et al. 2006).

Use of the AASHTO and FHWA approved GRLWEAP bearing graph has two distinct advantages over signal matching with PDA and CAPWAP analysis. First, according to the AASHTO code, site statistical variability work does not have to be completed since each pile is assessed by the inspector at the time of driving. Second, the bearing graph use is a deliberate activity using field pile performance and is completed to determine that each pile meets the limit state axial nominal capacity. This approach is discussed further in Section 1.4. The absence of statistical variation directives across a site in the AASHTO code, with GRLWEAP determined capacities, may not be an omission. Rather, the geotechnical site variations established by site investigations and by the design team may have been retained applying their own local state experience, knowledge, and judgment. This variation can then be incorporated in region-specific input of soil parameters into GRLWEAP, including soil side and tip quake and viscous damping parameters, as well as soil layering across the site.

For Oregon's pile driving conditions, considerable experience has been gained with steel pipe and $\mathrm{H}$ pile sections, especially for the silts, sands, and clays found throughout the Willamette Valley. The statistical studies reported in NCHRP 507 to establish $\varphi$ resistance factors for the AASHTO code used "default" soil and hammer parameters in GRLWEAP, have no restrike condition included to capture any known set-up, and which may be large in Oregon soils. The 
AASHTO-reported $\varphi$ values for static analysis are generally low, which precludes effective use of static analyses for nominal capacity evaluation. Essentially, static analyses are now relegated for use in establishing preliminary pile sizes and lengths for contract purposes only. Static analysis forms the basis of pile side shear to pile tip capacity ratios used in the GRLWEAP bearing graph and are most often established from uncertain SPT blow counts, statistically expressed by the published COV of 15 percent to 40 percent (Duncan 2000).

\subsection{THE WAVE EQUATION DYNAMIC APPROACH}

GRLWEAP version of the Wave Equation program calculates the induced stress and displacement waves traveling along the pile after a single hammer blow. It further assists in decisions about pile drivability and, more importantly, reports the static "equivalent" bearing capacity at the time of driving $\left(\mathrm{R}_{\mathrm{ult}}\right)$, by means of a bearing graph, when the field driving blow count is known. For illustration purposes only, Figure 1.1 presents an example of three bearing graphs with a range of possible $\mathrm{R}_{\mathrm{ult}}$ to driving blow counts per foot (blow/ft), illustrating hammer efficiency effects. When the field driving blow count is known, (Figure 1.1 illustrates a blow count of 68) the graph can be used to read the static $\mathrm{R}_{\mathrm{ult}}$ predicted by the program at the time of driving.

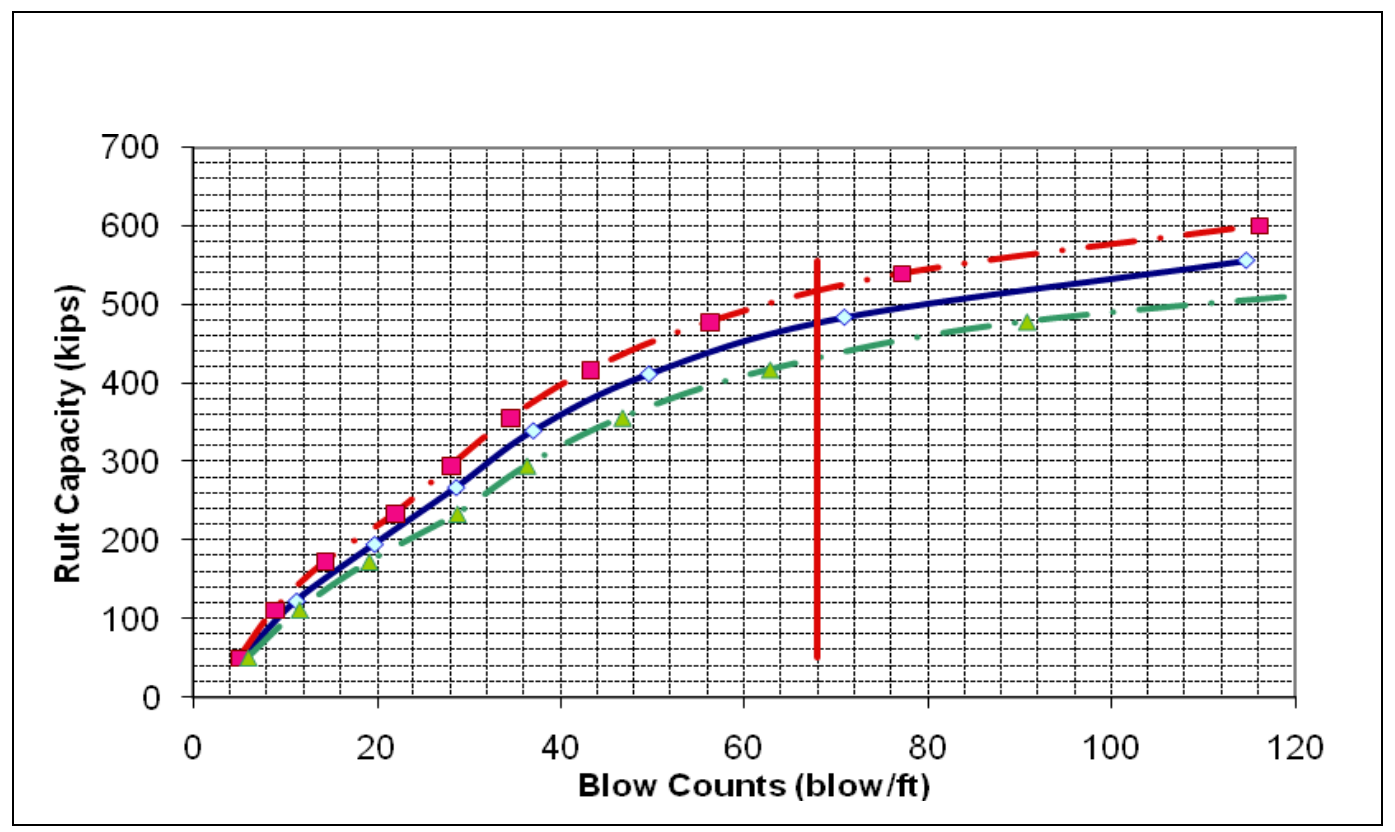

Figure 1.1: Example of GRLWEAP Bearing Graph

The ability to extract geotechnical bearing capacity information from GRLWEAP is made somewhat more difficult by the large number of site-specific variables, the modeling complexities, and the sensitivity of the output to all driving components, particularly the hammer efficiency. These site-specific variables include the equivalent soil "springs" elastic movement, called the Quake $\left(\mathrm{Q}_{\mathrm{i}}\right)$, and the soil springs viscous damping values $\left(\mathrm{J}_{\mathrm{i}}\right)$ for each soil-supported pile element. The typical application of GRLWEAP is often at two stages in design and construction: first, during the pre-bid period to establish that the pile designed by static methods can be driven by available equipment; and second, after the chosen contractor selects the final 
production hammer and driving accessories are known. At the second stage, the field bearing graph and hammer stroke to capacity plots, which control final penetration depths, are made available to the agency field inspector.

It is well known that pile long-term capacity will often show a capacity gain, called set-up, and very occasionally relaxation when the capacity drops. In these conditions, the use of measured driving blow counts at the end of initial driving (EOID) would yield conservative capacity results and the pile could be restruck after a waiting period (often a minimum of 24 hours) to give a more representative blow count. This is called the beginning of restrike (BOR) blow count, and any associated use of a bearing graph must be established from the soil resistance distribution appropriate after pile set-up. Even when static load tests have been conducted at the site, AASHTO recommends that GRLWEAP be used to extrapolate these test results to the production piles. GRLWEAP features include improved set-up models, as well as the use of the static pile capacity DRIVEN software code (Mathias and Cribbs 1998) for input of soil resistance distribution data to GRLWEAP.

During the late 1970s, the Ohio Department of Transportation and FHWA funded research regarding the installation of instrumentation to measure force and energy at the pile top. The resulting data yielded an advanced technology in understanding pile behavior. Subsequent private sector development has generated considerable success using the pile driving analyzer and advanced wave analysis by the CAPWAP program authored by GRL Engineers, Inc. (GRL) The program permits GRL to establish recommendations for soil static and dynamic properties, as well as likely static capacity at the time of pile driving. This advanced wave trace analysis is widely regarded as the most superior predictor of capacity, but it is accompanied by increased cost and time delay for the pile driving contract.

The AASHTO code assigns a CAPWAP $\varphi$ resistance factor value of 0.65 and calls for between 3 and 12 piles to be dynamically tested at BOR, depending on the number of piles at a given site and also the site variability. Equivalent static capacity can then be evaluated by either the GRLWEAP bearing graph format or the CAPWAP analysis of the hammer blow, or both. When associated with EOID and BOR conditions (to capture pile set-up), four capacity combinations are found: GRLWEAP-EOID, GRLWEAP-BOR, CAPWAP-EOID, and CAPWAP-BOR. All of the LRFD research reported in NCHRP 507, and incorporated in the AASHTO code, offers reliability-based $\varphi$ resistance factors for only three of these four combinations. The more costeffective GRLWEAP-BOR combination, which would capture pile soil set-up, was omitted without explanation.

This report discusses the strategy for completing this missing combination, GRLWEAP-BOR, by statistical reanalysis of the existing driven pile database for implementation by ODOT. This report also offers a technical basis for increasing the GRLWEAP $\varphi$ resistance factor above the present approved AASHTO value, during the transition period as the Phase 2 research is conducted. 


\subsection{IMPLEMENTATION ISSUES FOR OREGON}

\section{$2.1 \quad$ INTRODUCTION}

Regional and state DOT level implementation of the AASHTO code requirements should respect variations in soil behavior, site investigation practice, and local experience. Close examination of NCHRP 507 (which forms the basis of the AASHTO 2007 edition) reveals some reliance on "local judgment" and "experience" in the application of any field verification procedures to establish factored nominal resistance. Two disturbing trends in the report emerge which will limit flexibility for implementation of dynamic testing to local conditions: (1) the elimination of soil types as a variable when selecting $\varphi$ resistance factors to match the selected verification method, and (2) the previously reported absence of the GRLWEAP-BOR combination $\varphi$ resistance factor to be used after pile set-up has occurred.

To capture the transportation agencies' standard of practice, the code acknowledges that regional implementation can proceed after local recalibration efforts are complete. Based on the survey of DOTs conducted as part of this research study, some responses to the AASHTO code implementation are presented and discussed in Chapter 3. Any DOT is empowered by the code to recalibrate $\varphi$ resistance factors according to local practice and experience. "Regionally specific values should be determined based on substantial successful experience" (AASHTO 2007), including consideration of the following:

- Historically acceptable ASD factors of safety, F, and documented risk associated with F (see Section 2.4)

- Agency acceptable $\beta$ reliability values

- The effects of large pile groups offering high redundancy

- A statistical basis for nominal soil properties in static and dynamic models

In this chapter, an effort is made to introduce Oregon geotechnical issues, discuss load ratio effects on $\varphi$, and highlight code provisions. In addition, successful GRLWEAP practice for ODOT, understanding the derivation of $\varphi$ resistance factors based on past successful ASD use, and some geotechnical concerns, are briefly discussed.

\subsection{LOCAL PRACTICE}

No agency implementation policy or any application efficiency metrics are discussed in the AASHTO code to assist in the transition from ASD to LRFD. Historically, the ODOT Bridge Section has consistently followed the recommendations contained in all past and current FHWA recommendations for driven pile design and, since 2006, the code requirements set by AASHTO. One comparatively recent procurement change that modifies local DOT practice is the increased volume of design and analyses outsourced to the private sector consulting community. Such outsourcing begins with site investigation activities and is at present around 90 percent. It is 
likely to remain high. For most Oregon bridges, the economic constraints often set a minimum of one logged and sampled borehole per pier, with limited comprehensive laboratory shear strength testing. Soil conditions throughout the Willamette Valley, coastal development regions, and the Portland metropolitan area are predominantly sand, silt, and clay. Bridge foundation piles, typically steel pipe and $\mathrm{H}$ section piles, are of sufficient length to be primarily friction piles and these soils are known to exhibit set-up after EOID.

To replace the cost-prohibitive PDA dynamic monitoring and CAPWAP analysis, the ODOT preconstruction GRLWEAP activities use code default hammer efficiencies. After the selected contractor proposes hammer and driving accessories, and other specific details become known, bearing graphs giving the required minimum blow count for a nominal capacity are prepared for the inspector's use. ODOT has routinely used GRLWEAP for capacity in EOID and also occasionally at BOR if significant set-up was expected and the EOID capacity was low. In ASD, both EOID and BOR capacity values were used with the FHWA recommended factor of safety of 2.5. In the past, ODOT has also used the Modified Gates dynamic formulae. On occasion, additional CAPWAP and/or GRLWEAP work may be required of the piling contractor, using the services of an approved subcontractor. Oregon agencies have available the experience of Robert Miner of Robert Miner Dynamic Testing Inc., Seattle, Washington. In the past, his experience has permitted evaluation by GRLWEAP bearing graph of the pile set-up from EOID to BOR, as well as assessment of the gain coming from pile end bearing, identified from the end of restrike (EOR) blow count.

\subsection{GEOTECHNICAL CONSIDERATIONS}

Within any DOT, the accumulated foundation engineering knowledge base helps establish the accepted standard of practice. Pile design is set by site investigation results for which the amount of data, data quality, and interpretation are locally and regionally specific. This knowledge base within ODOT can be exploited to assist in implementation of the LRFD AASHTO code for bridge foundations to the agency. Much of the NCHRP 507 research findings removed the silt soil category, which is common in Oregon, with no specific recommendations offered for this soil type. However, the NCHRP 507 report does reveal a positive ratio of Davisson's capacity to predicted capacity bias greater than 1 for static methods in silt soils. It is also unclear why the AASHTO code declares dynamic methods unsuitable for overlying soft silts and clays when bearing is generated from the deeper and more competent soils; a combination which is present in Oregon. The code further cautions using the published $\varphi$ resistance factors when piles are over 600 millimeters $(\mathrm{mm})$ in diameter, but without citing reasons for this concern. The reason may be that no piles over this diameter were used in the statistical calibration.

As implementation of LRFD principles continues nationally, the outsourced geotechnical baseline site investigation information should begin to reflect the needs of reliability-based design. Often geotechnical practitioners under contract to ODOT will report conservative estimates of soil properties without regard for statistical consequences. The LRFD requirements are very specific in requiring both means and COV for reported properties (e.g., SPT N, undrained shear strength $\mathrm{S}_{\mathrm{u}}$, and apparent friction angles) to be available for foundation design. For pile design in Oregon silts, these properties may need to be available for both undrained and drained conditions, depending on the critical peak factored load conditions controlling the limit 
state design. Reliability studies to establish a $\varphi$ resistance factor attempt to distinguish between undrained methods for rapid loading and drained methods for slower loading. The code does alert practitioners to intermediate soils, such as Oregon silts, that may behave as undrained soils during driving but have characteristic loads with high dead load (compared to live load) applied slowly enough to behave as partially, or fully, drained soils. The outsourced practitioner community, which is not responsible for the LRFD field verification procedure and the corresponding $\varphi$ resistance factor, may not be alert to this subtlety.

\subsection{FACTORS OF SAFETY AND RELIABILITY}

The level of acceptable risk for bridge foundations under ASD is applied by use of the factor of safety, F, to reduce ultimate pile capacity to a maximum permitted load. This factor of safety was selected to accommodate key variables, such as critical loading type, soil variability, investment level in subsurface investigation, the method used to establish capacity (static or dynamic), and the consequences of failure. In all foundation engineering, these values have a typical range of 2 to 3.5 when the above key variables are considered. The derivation of the load and resistance factors under LRFD is intended to be statistically based; however, not all capacity design approaches have sufficient data available to accomplish this. The AASHTO code permits calibration of $\varphi$ by fitting to ASD factors of safety when insufficient data are available and significant, satisfactory local experience of ASD bridge foundation designs is available (as is the case for ODOT). This permits ODOT to set a realistic $\varphi$ resistance factor for use with GRLWEAP bearing graph at BOR in the transition period until the recalibration effort in Phase 2 is completed.

Both the FHWA pile manual (Hannigan et al. 2006) and the AASHTO-endorsed approach taken by Allen (2005a) contain the simple equations for a LRFD fit to ASD. These equations can be used to explore the role played by load factors and the DL to LL ratio for a structure. Allen cites Equation 2-1 below which, ignoring bias, relates $\varphi$ to $\mathrm{F}$ as a function of load factors $\gamma_{\mathrm{LL}}$ and $\gamma_{\mathrm{DL}}$ and the structure's DL/LL ratio:

$$
\boldsymbol{\varphi}=\left(\frac{\gamma_{\mathbf{D L}}\left(\frac{\mathbf{D L}}{\mathbf{L L}}\right)+\gamma_{\mathbf{L L}}}{\left(\frac{\mathbf{D L}}{\mathbf{L L}}+\mathbf{1}\right) \mathbf{F}}\right)
$$

Both Allen (2005a) and Long (2002) encourage the use of a DL/LL ratio of 3 to establish $\varphi$. Using the current load factors from AASHTO Strength I from provisions 3.4.1 $\left(\gamma_{\mathrm{LL}}=1.75\right.$ and $\left.\gamma_{\mathrm{DL}}=1.25\right)$ with this DL/LL ratio for ultimate limit state, Equation 2-1 reduces to:

$$
\varphi=\frac{1.375}{F}
$$


The AASHTO code provisions suggest that longer steel bridges ( $>60$ meter span) will have higher DL/LL ratios $(\geq 9)$ and occasionally the ultimate limit state Strength IV controls. Setting $\mathrm{DL} / \mathrm{LL}$ ratio of 9 for these structures, and with AASHTO load factors from provisions 3.4.1-2 $\left(\gamma_{\mathrm{LL}}=0\right.$ and $\left.\gamma_{\mathrm{DL}}=1.5\right)$ Equation 2-1 reduces to:

$$
\varphi=\frac{1.35}{F}
$$

Both of these equations assume the actual nominal resistance $R_{k n}$ has no bias, $b_{R}$ (mean resistance/nominal resistance), when measured against Davisson's capacity and illustrate only the connection of $\varphi$ to load factors and the DL/LL ratio.

For further illustration, if Equation 2-1 is rearranged and the use of LL/DL ratio is used (not $\mathrm{DL} / \mathrm{LL}$ ) under even higher dead loads and with the bias, $b_{R}$, introduced, then Equation 2-1 is restated by Salgado (2008) as Equation 2-2 below:

$$
\boldsymbol{\varphi}=\mathbf{b}_{\mathrm{R}}\left[\frac{\gamma_{\mathrm{DL}}+\gamma_{\mathrm{LL}}\left(\frac{\mathbf{L L}}{\mathrm{DL}}\right)}{\left(\frac{\mathbf{L L}}{\mathbf{D L}}+\mathbf{1}\right) \mathbf{F}}\right]
$$

This equation now can illustrate the role played by DL/LL ratios greater than 9 . For the current LRFD load factors (AASHTO 2007) with provisions in Table 3.4.1-1 and Table 3.4.1-2, and setting LL/DL ratio to zero (i.e., DL/LL $\rightarrow \infty$ ) for Strength IV, the result is ${ }^{1}$ :

$$
\boldsymbol{\varphi}=\frac{\mathbf{b}_{\mathrm{R}} \gamma_{\mathrm{DL}}}{\mathbf{F}}=\frac{\mathbf{b}_{\mathrm{R}} 1.5}{\mathbf{F}}
$$

Then setting $b_{R}$ at 1 to ignore any bias, the Strength IV on large steel bridges suggests that $\varphi$ resistance factors are higher (by $11 \%$ ) to achieve the same $F$ compared to the common Strength I. NCHRP 507 provided the bias that may be included in Equation 2-2 to recognize the mean ratio of Davisson's capacity to predicted capacity at the EOID in all soils. This was reported as 1.656 for GRLWEAP-predicted nominal capacity and 1.626 for CAPWAP predicted nominal capacity. The effect of this NCHRP 507 bias across the range of typical F values for GRLWEAP is listed in Table 2.1 for the more common Strength I ultimate limit state load factors using Equation 2-2. NCHRP 507, Table 27, also indicates that GRLWEAP capacities have an economic performance efficiency measurement for redundant piles of 0.24 , which is greater than the CAPWAP capacity efficiency of 0.16 . Taken together, the bias and efficiency issues imply an advantage to ODOT in continuing with GRLWEAP field bearing graph evaluation of capacity.

\footnotetext{
${ }^{1}$ NCHRP 507 gives $\varphi=1.4167 / \mathrm{F}$ for $\mathrm{LL} / \mathrm{DL}=1 / 2$ without considering bias.
} 
Table 2.1: GRLWEAP Resistance Factors by Fitting to ASD for Strength I

\begin{tabular}{c|l|l|l|l|l|l|l}
\hline \multicolumn{4}{c|}{$\varphi$ WITHOUT NCHRP 507 BIAS } & \multicolumn{5}{c}{$\varphi$ WITH NCHRP 507 BIAS } \\
\hline $\mathrm{F}$ & 2.5 & 2.75 & 3.0 & $\mathrm{~F}$ & 2.5 & 2.75 & 3.0 \\
\hline$\varphi$ & 0.55 & 0.5 & 0.458 & $\varphi$ & 0.91 & 0.828 & 0.758 \\
\hline
\end{tabular}

It is known that fitting to ASD does not accommodate statistical variations in any method's prediction. Also, the $\varphi$ values listed in Table 2.1 take no account of the COV of the spread of Davisson's capacity to GRLWEAP capacity ratio. The table treats the GRLWEAP capacity prediction as a deterministic value, and incorporating bias in $\varphi$ without a statistical load test database effort, for Oregon, from ASD calibration is not a long-term recommendation for ODOT. Table 2.1 does, however, provide a check on how reasonable the stated AASHTO $\varphi$ resistance factor is, and it offers a basis to support increasing the $\varphi$ resistance factor. There are no reported foundation failures in Oregon, therefore engineering judgment permits making use of the low probability of failure for pile foundations in ODOT, which as designed by ASD is likely to have actual $\mathrm{F}$ values higher than those presented in Table 2.1. 


\subsection{PRACTITIONER SURVEYS}

\subsection{FHWA NCHRP 507 SURVEYS}

As discussed earlier, the major research effort to guide transition to LRFD for deep foundations was undertaken with the AASHTO sponsored NCHRP 507 study (Paikowsky et al. 2004). The work began in 1997, and attention was given to documenting the present state of practice across the nation's DOTs through the use of two surveys. The first of these was a simple letter survey conducted by the FHWA Fort Worth, Texas, Region in May 1999 to gauge each state's use of AASHTO standard specifications. The survey, consisting of four questions, was considered "informal" and "unofficial." The fourth question gauged each state's commitment to LRFD implementation. Response rate, from the 298 individual surveys that were sent out, was 14 percent and the responses represented 32 of the 50 states. Conclusions from this survey relevant to the present study are summarized below:

- Only 18 states routinely used AASHTO specifications for foundation design.

- Only 14 states were committed to implementing LRFD.

- No states had current copies of all four AASHTO-listed specifications for pile design.

- Many states commented that both consultants and DOT design professionals would be required to adopt LRFD and that "...additional research should be performed which reflects local practice and soils...."

This unofficial survey result led the NCHRP 507 research group in August 1999 to develop and analyze a more comprehensive survey covering specific pile and drilled shaft practice. The second survey was directed toward DOT practice and contained no regional questions that might assist final implementation on a state-by-state basis at the completion of the research. In addition to capturing DOT practice for driven pile design and capacity verification, the survey provided the authors of NCHRP 507 with an opportunity to enquire after additional load tests and pile driving data, including restrike, for use in their research. A total of 42 specific questions covered foundation alternatives, driven piles, and drilled shafts. Generalized conclusions from the survey answers, covering foundation types and practice on driven piles for 43 states and relevant for this present study, reveal the following:

- 75 percent of all states used driven piles and 64 percent preferred driven piles. For the driven piles, 53 percent used $\mathrm{H}$ piles and 25 percent used closed end pipe piles.

- The most common dynamic capacity method was GRLWEAP, with 80 percent of states using this software. 
- 86 percent of the states used SPT blow counts to establish primary properties-93 percent of states were designing by ASD, and 30 percent employed LRFD (clearly, most of these states did both ASD and LRFD design).

- For establishing production pile length to achieve capacity (note that in 1999 this was by ASD methods), 52 percent of states used BOR.

- The estimated probability of failure for a group of piles was stated as "unknown" by 67 percent of states. Only 14 percent of the states had experienced any pile "failure."

Taken collectively, the two surveys from 1999 indicate that practice standards for ODOT in pile design are typical of the nation's DOTs as a whole. The survey responses suggest that the most relevant combination of pile type, capacity verification, and calibration for a $\varphi$ resistance factor should include driven $\mathrm{H}$ piles using GRLWEAP at BOR for satisfactory probabilities of failure corresponding to an ASD factor of safety between 2.0 and 3.0. However, this combination was not pursued in the NCHRP 507 report, nor is it represented in any subsequent editions of AASHTO's LRFD Bridge Design Specifications since that time.

\subsection{NORTHWEST 2007 SURVEY}

As part of the present study effort, a survey of current pile design practice regarding LRFD in Northwest states was conducted in August 2007 and reported by the FHWA-Western Federal Lands Highway Division. The results were presented and a discussion held at the FHWA Northwest Conference at Coeur d'Alene, Idaho, on September 5, 2007. The survey questions were designed by the Phase 1 study advisory group comprising Jan Six (ODOT), Tony Allen (WSDOT), Richard Barrows (FHWA), and report author Trevor Smith (Portland State University). The survey's objective was to assess the overall use of GRLWEAP in Northwest DOT practice, the response of state foundation engineers to AASHTO GRLWEAP $\varphi$ resistance factors, and the estimated number of possible future bridge construction projects to gauge economic impact of the AASHTO code.

The survey consisted of 15 questions that were designed to reveal the methods in use by the participating DOTs for driven pile designs and the role of GRLWEAP. The survey was e-mailed to the Steering Committee members of the Northwest Geotechnical Workshop on August 8, 2007. The respondents were asked to return the completed survey by e-mail no later than August 27, 2007. Complete response details of the survey are provided in Appendix A. Survey questions and responses were compiled in a PowerPoint ${ }^{\circledR}$ presentation to stimulate group discussion among the Steering Committee members, as well as other representatives within the participating DOTs at the conference. Summary survey findings were:

- Very heavy "GRLWEAP only" use is identified as the largest dynamic category for determining final pile penetration depths. It is also used 80 percent of the time for pile drivability and hammer approval.

- 22 percent of the states have delayed LRFD implementation until the final AASHTO permitted date of October 1, 2007. 
- GRLWEAP use in both EOID and BOR is used over 60 percent of the time. However, no consensus exists for the BOR definition or the wait time after EOID before the restrike.

- $\quad 37.5$ percent of respondents do not use the AASHTO-sanctioned resistance $\varphi$ resistance factor of 0.4 with GRLWEAP.

- Approximately 80 percent of respondents believe a $\varphi$ of 0.4 is conservative but are not engaged in any effort to recalibrate this factor at this time.

- Across the Northwest states, approximately 400 pile-supported bridges are expected to be designed in the next 5 years as part of a total of 750 in the next 10 years.

- Interest by survey participants in a future Phase 2 of this study to conduct a recalibration of the 0.4 factor is very strong, with over 60 percent of states willing to assist.

The survey and its results were also discussed at the FHWA National Geotechnical Conference in Boise, Idaho, held on September 18, 2007. Additional LRFD dynamic capacity verification surveys to update the current national DOT picture are being conducted by Tony Allen as Vice Chair of AASHTO T-15 Technical Subcommittee for Bridge Foundations and Walls. It does not appear any surveys have been directed toward the consulting sector, whose members are increasingly responsible for implementation of LRFD requirements, including site investigation, design, and construction monitoring. 


\subsection{OREGON LRFD CASE HISTORIES}

\subsection{INTRODUCTION}

Local practice employing GRLWEAP at both EOID and BOR conditions, as discussed in Chapter 2, has served ODOT well. ODOT has routinely used GRLWEAP in EOID and also at BOR if significant set-up was expected and EOID capacity was low, both conditions with the FHWA recommended factor of safety of 2.5 in ASD. This chapter summarizes a study intended to gauge the effect of the LRFD requirements in AASHTO on two significant ODOT bridges constructed in the past 25 years under ASD. Two sites were offered by ODOT to be studied. These sites are the Interstate 205 (I-205) Bridge over the Columbia River, opened in 1977, and the Corvallis Bypass Bridge, opened in 1990, which crosses the Willamette and Marys rivers.

The study originally intended to use GRLWEAP bearing graphs, CAPWAP nominal capacities, and static load test results to compare axial capacities under LRFD principles on test piles at the two bridge sites. The nominal capacity predictions from GRLWEAP bearing graphs representing the two sites (based on input supplied by ODOT) were to be compared to the CAPWAP results at Corvallis and to the static load results at I-205 for a single test pile at each site. The economic effects of the LRFD-based AASHTO specifications were to be studied by evaluating the bridge sites and determining the difference in the number of piles required under LRFD design compared to the "as-built" piles under ASD. The study also included examination of the frequency of pile dynamic testing and static load testing required at the bridge sites based on AASHTO statistical site variability provisions in its most recent edition of the code (2007).

The Corvallis Bypass Bridge construction included both PDA and CAPWAP analysis data for both EOID and BOR at a number of test piles. In addition, the as-built structural loads were available at this site to calculate differences in pile numbers under the different axial capacity methods. The I-205 Bridge construction activities included full-scale load testing on selected preconstruction test piles. The final production piles at the I-205 site were all of different sizes compared to the load test piles; no structural loads were available; and no comparison to new LRFD requirements could be made.

AASHTO outlines five methods for analyzing the capacity of driven piles, each requiring a specific combination of processes for determining the driving criteria and establishing quality control. To gain insight into design and testing for these bridge foundations under the new AASHTO code, the research group examined the amount of CAPWAP analysis and static load testing which would currently have to be conducted on test piles, based on site variability. It is important to note that these new LRFD field pile testing quantities were not required to be met at the time of either the Corvallis or I-205 bridge design and construction. 


\subsection{SOIL VARIABILITY}

Of particular interest in these case studies are the geo-statistical features of the two study sites and how these sites comply with the new AASHTO required soil investigation and field capacity testing frequencies. Neither AASHTO nor FHWA offer much guidance for the detailed statistical manipulation of the supporting data for the "site" definition in the code. This study provided an opportunity to explore this omission. AASHTO includes provisions to declare subsurface conditions reasonably uniform across a "site," and thus allows the bridge project to possibly encompass multiple sites. AASHTO specifies that a site variability analysis be conducted, with a resulting COV calculated to assign a descriptor to the site as High, Medium, or Low variability. A COV less than 25 percent is Low, between 25 percent and 40 percent is Medium, and greater than 40 percent is High. (The code calls for more pile testing in soils with higher variability.) Defining the COV for a site ensures that an appropriate number of piles are tested for the project. This study made a distinction between the total site variability using all subsurface information $\left(\mathrm{COV}_{\mathrm{T}}\right)$ and the more local pile site variability $\left(\mathrm{COV}_{\mathrm{P}}\right)$, which recognizes the actual depth of soil influenced by the pile.

In accordance with the AASHTO code, the $\mathrm{COV}_{\mathrm{T}}$ serves to statistically classify the soil and provides insight into the variation of the soil layers across the whole project. The $\mathrm{COV}_{\mathrm{T}}$ is generated for all of the soil deposits identified for the project. For the two ODOT bridges, $\operatorname{COV}_{\mathrm{T}}$ was based on SPT blow counts with outliers capped at 50 blows per foot. Outliers were defined as any SPT test with blow counts higher than 50 and/or penetration less than 18 inches. In accordance with AASHTO directives presented in commentary section C10.5.5.2.3, the SPT values for each stratum layer in a borehole at the ODOT sites were averaged; each of the borehole averages were then averaged across the project site to generate the average SPT blow count and $\mathrm{COV}_{\mathrm{T}}$ value for the entire site. This exercise was completed for both bridge sites and is discussed and reported in greater detail below. The $\mathrm{COV}_{\mathrm{P}}$ was determined for the selected test pile and included only the soil layers that were within the depth range of pile penetration identified by borings within a 200 -foot radius. The $\mathrm{COV}_{\mathrm{P}}$ for each layer was generated from the normalized site SPT blow counts and followed the AASHTO requirements outlined in section 10.4.6.2.4 (AASHTO 2007), which limit the SPT blow count to a maximum of 50.

\subsection{DRIVING CRITERIA AND QUALITY CONTROL}

AASHTO (2007) outlines five methods for field control and verification of the nominal capacity of driven piles, as summarized below:

1. A static load test to establish driving criteria, with quality control by dynamic testing with a pile driving analyzer or a calibrated wave equation (GRLWEAP). Static load tests are conducted after a period of set-up. (This implies that the load test results are appropriate for a BOR dynamic testing condition.)

2. Dynamic testing with signal matching (CAPWAP) at BOR conditions with quality control by dynamic testing and/or a calibrated wave equation.

3. GRLWEAP bearing graph at EOID. 
4. Modified Gates driving equation using the final pile blow counts at EOID.

5. Engineering News Record dynamic pile formula at EOID.

Currently, ODOT, consistent with many DOTs, uses a hybrid of method 3 to analyze and control the pile penetration and determine nominal capacity. This hybrid method calls for GRLWEAP combined with EOID, and also BOR driving conditions if capacity is low at EOID. There is some evidence that this method is common among DOTs, based on the surveys discussed in Chapter 3. GRLWEAP bearing graphs are a function of the soil profile (as well as the hammer and driving accessories) and of the side friction to total capacity ratio, which is established by a static analysis. FHWA's program software DRIVEN (Mathias and Cribb 1998) conducts a static vertical capacity analysis of the pile using the Tomlinson method in clays and the Nordland/Thurman method in sands, among others (Hannigan 2006). The output for DRIVEN is conveniently in GRLWEAP input file format and contains the static capacity as a function of depth, the tip and side capacity distribution, and soil profile information.

At preconstruction, ODOT evaluates several types of hammers from the GRLWEAP library and establishes that the pile can be driven at the site to the required tip elevation and bearing capacity. Part of this analysis is the selection of soil spring coefficients for side and toe damping and the spring "elastic" quake. Verification and modification of these soil coefficients may occur if ODOT has the pile PDA analyzed and a CAPWAP analysis performed. Once the contractor has confirmed hammer and driving accessories, a bearing graph and stroke predictions are generated for use by the production conditions inspector. The reported installation blow count of the pile is monitored and nominal capacity evaluated by comparing the embedment depth-based blow counts of the field pile to the bearing graphs.

\subsection{CORVALLIS BRIDGE STUDY ZONE 1}

The Corvallis Bypass consists of five bridges (including on- and off-ramps) constructed over the Willamette and Marys rivers and founded in undrained cohesive silts and clays. The Willamette River Bridge (Bridge No. 16873) is approximately 450 feet long with four spans. There are five bents: 1, 2, 3, 4, and 5 with 16,32,38, 44, and 44 piles driven, respectively, for a total of 174 piles in seven ODOT zones. In selecting a test pile from the appropriate zone for this study, certain pile characteristics were important: known tip conditions, CAPWAP monitoring during driving, detailed soil data available, and complete driving logs to allow study of both EOID and BOR. These requirements eliminated most of the zones and highlighted Zone 1 and Zone 3 as candidates for study. Zone 1 piles are mostly embedded in silty clay, while Zone 3 piles are in layered deposits of silty clay and sandy gravel. Since the focus of this research effort relied on consistently uniform soil deposits, Zone 1 was selected. The test piles driven in Zone 1 were 12.75 inch diameter steel pipe piles, with total embedment depth between 24 and 88 feet.

ODOT practice, at that time, closely matches the current AASHTO method 3. (The Corvallis study site also falls under the second method because there was dynamic testing with CAPWAP wave analysis.) ODOT used an FHWA approved combination of capacities from BOR and 
EOID to estimate pile capacity as a linear function of embedment depth. This step was required because production piles were of different lengths. The current AASHTO method 2 has a $\varphi$ resistance factor of 0.65 , and method 3 has a $\varphi$ resistance factor of 0.4 . Part of the intent of this study is to demonstrate that combining wave equation analysis with BOR conditions actually justifies a higher $\varphi$ resistance factor. It is significant that ODOT combined the two methods in its capacity approach at Corvallis.

\subsubsection{Site Investigation and Pile Testing}

Subsurface explorations for the project were completed in 1989. The site is in the immediate vicinity of two rivers and the soil profile primarily consists of layers of silt and clay. Each ODOT zone is similar except for a slight variation in the gravel layers. The site has five major layers extending from mudline level: sandy clay, silty sand, sandy gravel, silty clay to clay, and siltstone at depth. This layering sequence is typical (though thickness varies) throughout the site. In the selected Zone 1, there are 5 to 17 feet of silty sand, 15 to 20 feet of sandy gravel, and silty clay at depth.

The results of PDA tests on 14 production indicator piles for the complete bridge were analyzed in 1990 with CAPWAP. In Zone 1, three borings were advanced with laboratory testing to classify the soils and two test piles received CAPWAP analysis. The test piles were driven in a location in pile Bent 3, Zone 1, which does not include the silty sand or sandy gravel layers. Test pile 1 (TP-1) was analyzed in this study for both EOID and BOR, and test pile 2 (TP-2) was analyzed for EOID only.

Laboratory testing for the entire bridge site included four Triaxial tests (two unconsolidated undrained (UU) tests and two consolidated undrained (CU) tests) four Consolidation tests, Atterberg limits, sieve analysis, specific gravity, unit weight, and natural moisture content determinations. It should be noted this is consistent with AASHTO (2007) which specifies that strength testing for the determination of the undrained shear strength of cohesive soils should come from CU and UU Triaxial tests, combined with in-situ tests, and should be plotted as a function of depth for extensive and deep (6.0 meters or more) cohesive layers. The primary soil exploration testing at the Corvallis site was by SPT. Therefore, these test results were selected as the soil parameter to determine site variability. The silty clay and clayey silt at the site was calculated to have a $\mathrm{COV}_{\mathrm{T}}$ of 16 percent. This is categorized as low variability, according to AASHTO 2007. Under the current code, if CAPWAP had been selected as the method of dynamic capacity verification testing, ODOT would have been required to conduct at least one wave trace analysis test per pier and no less than four tests per site for Zone 1. By coincidence, both these requirements at this site are identical since Zone 1 has four piers.

\subsubsection{GRLWEAP Bearing Graph and CAPWAP Nominal Capacities}

For this study, GRLWEAP was used to generate a bearing graph based on key parameters such as toe quake, side damping, and hammer details supplied by ODOT (as used in construction) and 
the tip to side resistance distribution generated by DRIVEN. Figure 4.1 shows the bearing graph generated under the supplied ODOT parameters. More extensive studies, as well as detailed analyses beyond this study scope, are reported by B.R. Jackson (2008).

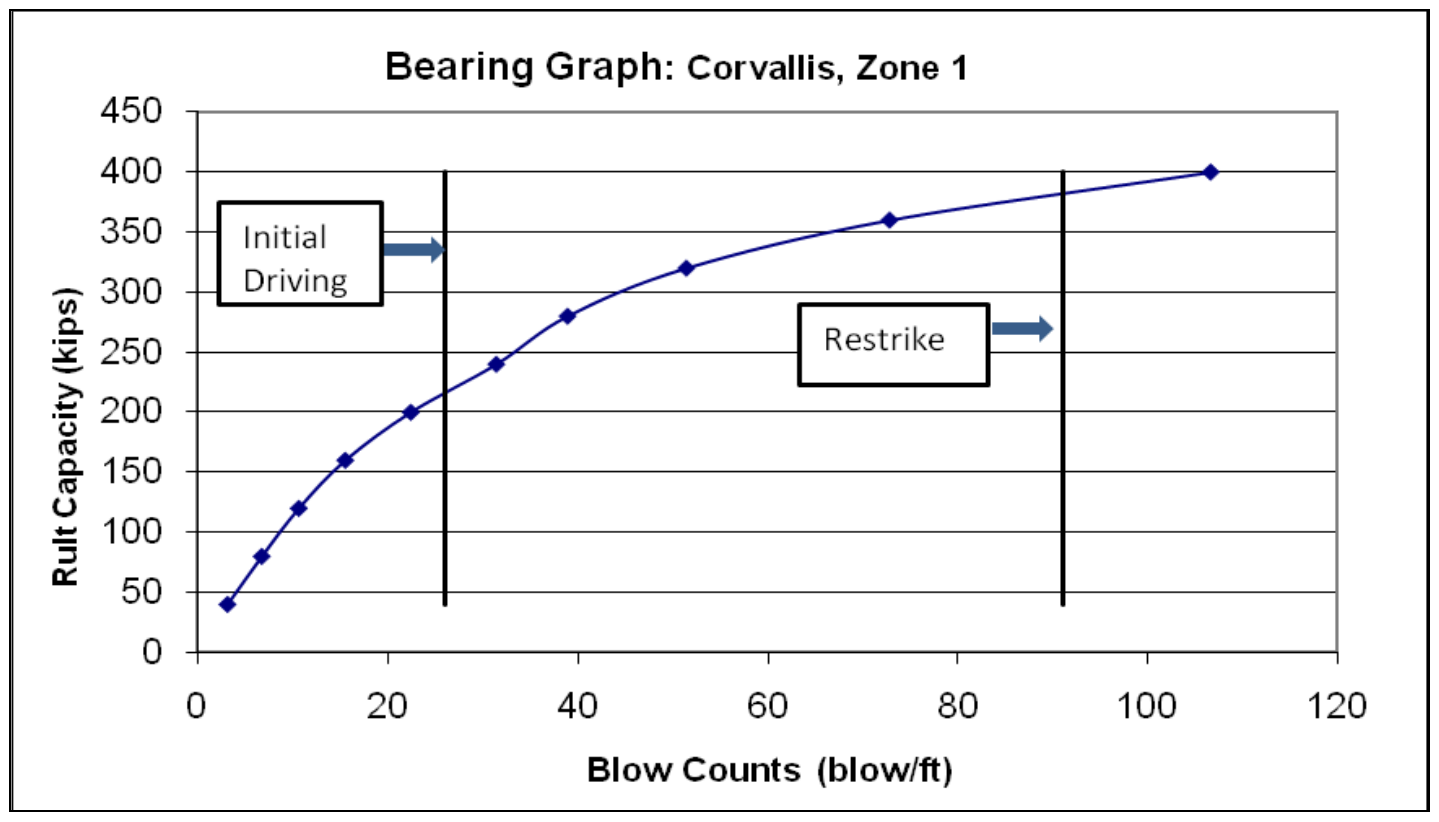

Figure 4.1: Bearing Graph: Corvallis, Zone 1 Bent 3 TP-1

The governing LRFD equation for determining the required number of piles is given in Equation 1-1 (section 1.1.2). The individual identification for summation of load sources was not supplied by ODOT, and they have endorsed the use of a single load factor for this study. Therefore, the load summation reduces to a single factor and Equation 1-1 for Bent 3 becomes:

$$
\gamma_{\mathrm{ij}} \mathbf{Q}_{\mathrm{ij}} \leq \boldsymbol{\varphi}_{\mathrm{k}} \mathbf{R}_{\mathrm{nk}}
$$

Where $Q_{i j}$ is the structural load, $R_{n k}$ is the nominal axial capacity, $\varphi_{\mathrm{k}}$ is the LRFD AASHTO resistance factor, and $\gamma_{\mathrm{ij}}$ is the LRFD load factor. The nominal axial capacity of the piles was determined at EOID and BOR using GRLWEAP and reported for BOR only, by CAPWAP analyses.

The ultimate GRLWEAP determined nominal axial capacity shown in Figure 4.1 is 216 kips for EOID field blow count and 382 kips for BOR blow count, at the embedment depth of 44 feet for TP-1. To calculate the GRLWEAP bearing capacities for the as-built embedment depth of 58 feet in Bent 3, TP-1 EOID and BOR capacity values were used by ODOT in 1990 in a depth interpolation. ODOT assumed that the percent increase from BOR on TP-1 to BOR on the deeper TP-2, as measured from the CAPWAP results, would be the same for the GRLWEAP results on the two piles at both EOID and BOR. The GRLWEAP nominal axial capacity values for the production piles were then 275 kips and 457 kips for EOID and BOR, respectively, at 58 
feet embedment. For this embedment depth, the corresponding CAPWAP capacity values were 295 kips and 407 kips for EOID and BOR, respectively.

Using the AASHTO $\varphi$ resistance factors of 0.4 and 0.65 for GRLWEAP and CAPWAP, respectively, and their corresponding nominal axial capacities, the calculated percent difference in pile numbers required to satisfy Equation 4-1 can be determined. These changes in the number of piles required are assumed to be for piles driven to the same length and driving resistance - not a deeper embedment depth (which is the more likely option to be called for at the time of driving). The percent difference in the number of piles is rounded up to an integer to calculate the number of piles required to meet, or exceed, the factored load at Bent 3 . Table 4.1 summarizes the results of this exercise for GRLWEAP and CAPWAP determined nominal capacities. ODOT reported the as-built combined structural load on Bent 3 at 6,840 kips, and endorsed the $\gamma_{\mathbf{i j}}$ LRFD load factor at 1.4. That resulted in a factored design load of 252 kips to be assigned for each of the as-built 38 piles at Bent 3 .

Table 4.1: GRLWEAP and CAPWAP Determined Number of Piles at Bent 3

\begin{tabular}{l|l|l|l|l|l}
\hline Practice Scenario & $\begin{array}{l}\text { Nominal } \\
\text { Resistance, } \\
\mathbf{R}_{\mathbf{n k}}\end{array}$ & $\begin{array}{l}\text { Factored } \\
\text { Resistance } \\
\text { (kips) } \varphi \mathbf{R}_{\mathbf{n k}}\end{array}$ & $\begin{array}{l}\text { Percent } \\
\text { Change }\end{array}$ & $\begin{array}{l}\text { Required } \\
\text { No. of } \\
\text { Piles }\end{array}$ & $\begin{array}{l}\text { Change in No. of } \\
\text { Piles Compared } \\
\text { to As-Built }\end{array}$ \\
\hline $\begin{array}{l}\text { GRLWEAP(EOID) } \\
\varphi(=0.40)\end{array}$ & 275 & 110 & 129.4 & 87 & 49 \\
\hline $\begin{array}{l}\text { GRLWEAP (BOR) } \\
\varphi(=0.40)\end{array}$ & 458 & 183 & 37.9 & 52 & 14 \\
\hline $\begin{array}{l}\text { CAPWAP (BOR) } \\
\varphi(=0.65)\end{array}$ & 407 & 264 & -4.6 & 36 & -2 \\
\hline $\begin{array}{l}\text { GRLWEAP (BOR) } \\
\text { to match as-built } \varphi \\
(=0.55)\end{array}$ & 458 & 251 & 0.3 & 38 & 0 \\
\hline
\end{tabular}

The first practice scenario summarized in Table 4.1 reflects the current AASHTO 2007 requirements. Using GRLWEAP at EOID conditions for Bent 3 would require an extra 49 foundation piles to be driven - an increase of 129 percent above the 38 piles actually installed under ASD. Employing the ODOT current practice of moving to BOR data for piles that are likely to show set-up and have low EOID capacities with the AASHTO $\varphi$ resistance factor of 0.4 would require 14 more piles - a 38 percent increase. However, the use of CAPWAP determined nominal capacity values confirmed that the final as-built number of piles at this Bent actually did satisfy Equation 4-1 by having two extra piles (only 36 would have been required). If this CAPWAP result is viewed as confirmation that the 1990 as-built Bent 3 foundation would comply fully with the present LRFD requirements, then it can be used to measure the change in $\varphi$ resistance factor for GRLWEAP at BOR to achieve the same AASHTO required number of piles. This is presented in Table 4.1 as the final practice scenario.

In conclusion, the 0.55 back-calculated $\varphi$ resistance factor agrees with that calibrated from ASD for the actual factor of safety, F, used by ODOT in the 1990 pile design and construction, as summarized in Table 2.1 (without NCHRP 507 reported bias). Furthermore, at Bent 3, the 
number of piles is in full compliance with the current AASHTO 2007 code when checked by CAPWAP at BOR under the as-built loading requirements. If Bent 3 is representative of the entire bridge foundation, then full compliance is shown to current standards; however, use of the current AASHTO resistance factor $(\varphi=0.4)$ for GRLWEAP at EOID may have required over twice as many piles.

\subsection{INTERSTATE I-205 STUDY SITE H}

The I-205 Bridge over the Columbia River is approximately 11,790 feet long, spanning from Marine Drive on the Oregon side to the Lewis and Clark Highway in Washington ( $\mathrm{CH} 2 \mathrm{M} \mathrm{Hill}$ 1974). ODOT identified eight "sites" for investigation (indicated as Sites A through $\mathrm{H}$, covering a total of 40 spans with an average length of 286 feet (ODOT 2007). Site investigation for the I205 Bridge began in 1971 and was concluded in 1974. The bridge was opened December 1982. The final approved piles driven during construction were of a different cross section and depth from those in the load test program. All driving logs were supplied to the study group by ODOT however, structural loads were not. This prevented a complete application of AASHTO Equation 4-1 because the number of as-built piles required to carry the factored load cannot be determined.

In selecting the appropriate site, the study group focused on the locations where testing was performed on the friction piles. For the I-205 Bridge, just over half of the pile foundations were end-bearing, and they were driven in locations that had little frictional contribution due to the relatively thin soil layers. The exceptions were Sites A, F, G, and H, where the soils were thick enough to merit friction piles. All of those sites contained static load testing on both steel and concrete piles and had piles gaining side friction capacity primarily from sand (the overlying cohesive layers were isolated by steel casings). A total of 14 piles were load tested; however, only Site $\mathrm{H}$ had a pile tested under restrike conditions. All the piles were allowed to set up for a minimum of 24 hours, as set forth in the project specifications. The test piles driven were HP 14 X 89 and W 14 X 150 steel piles and 14-inch and 16.5-inch diameter precast reinforced concrete piles. The piles were embedded from 10 to 91 feet deep. The selected steel pile at Site $\mathrm{H}$ was tested under EOID and repeated restrike conditions, consisting of two occasions of redriving and retesting, with variable periods of set-up, greater than 24 hours, in between.

For the I-205 Bridge, the ODOT practice that matches the AASHTO specifications listed in Section 4.3 was the first method, with driving criteria established from static load tests. The minimum driving resistance was combined with the minimum hammer energy (for quality control), and the test pile hammer was used for the production piles. Under the current AASHTO code, the $\varphi$ resistance factor to be used is based on site variability and the total number of test piles. Site $\mathrm{H}$ showed a high variability, and two piles were load tested at this site: one concrete and one steel. The steel $\mathrm{H}$ pile was re-driven and load tested twice (for a total of three static tests). This repeat load test can be interpreted to give a resistance factor from AASHTO Table 10.5.5.2.3-3 of 0.75 (for three tests) or, if the concrete pile were also counted (four tests total), a resistance factor of 0.80 . This site also brings into question the definition of the restrike condition: at what point of pile movement does the transition from BOR to continual driving conditions actually occur? The significance of the BOR definition is considered critical to establish the reliability of combining wave equation BOR analysis with nominal capacity tests - in this case, from static load testing. 


\subsubsection{Site Investigation and Pile Testing}

Most of the soils at the I-205 Bridge consist of dense to very dense sand, silty and clayey sand and gravel, and sandy gravel. The more uniform and extensive sand on the Oregon side was the location for the majority of the pile load tests. The Troutdale Formation, a dense conglomerate layer of gravel and sand, lies at depths varying from 10 to 120 feet, on the Washington and Oregon side, respectively. There is a deep layer of very stiff clayey silt and silty clay located more than 140 feet below the riverbed on the Oregon side. Specifically, at Site H 10 to 40 feet of clayey silt to silty clay are underlain by 120 feet of fine to medium sand, which is further underlain by a dense conglomerate layer (i.e, the Troutdale Formation). Borings B-52, B-53, and B-54 are located adjacent to the area where the test pile was driven; no other known borings are within 200 feet of the site and no laboratory test data are available for these borings.

Two consolidated drained (CD) Triaxial tests and two Consolidation tests were completed, as well as numerous sieve analyses for grain size determination. In addition, SPT tests were performed at 5-foot intervals in each of the 37 borings for the section of the bridge selected in this study.

The most prevalent form of field testing at the bridge site was SPT during the exploration phase; therefore, it was chosen to evaluate the site variability condition under the current AASHTO code. AASHTO specifies that the drained friction angle of granular soils should be correlated to SPT or CPT tests, along with correlations to particle size. The medium sands that make up the soil profile at Site $\mathrm{H}$ were found to have a coefficient of variability, $\mathrm{COV}_{\mathrm{T}}$, of 42 percent, which is classified as highly variable according to AASHTO commentary C10.5.5.2. ODOT conducted two static tests at that site $\mathrm{H}$, which would be matched by a resistance factor of 0.65 according to AASHTO; however, note that final selected pile types and lengths were different from the load test piles. If the restrike cases were counted as static tests also (since a static test was actually conducted for each one), that would be a total of four static tests, which permits an increase to the AASHTO resistance factor up to a value of 0.80 .

\subsubsection{GRLWEAP Bearing Graph}

Site $\mathrm{H}$ was chosen since the restrike condition on the steel $\mathrm{H}$ pile allowed for both EOID and BOR comparisons. Unfortunately, the driving logs for both redriving events did not record the initial restrike blow counts. In this study, they were assumed to be equal to the ending blow counts for the previous EOID. The lack of driving logs made it impossible to determine the amount of pile set-up. A GRLWEAP analysis was conducted for the EOID condition; soil parameters such as toe quake, side damping, and hammer details were supplied by ODOT. Figure 4.2 shows the bearing graph constructed from default GRLWEAP input and input established from the DRIVEN program for test pile, TP-1 at Site H. 


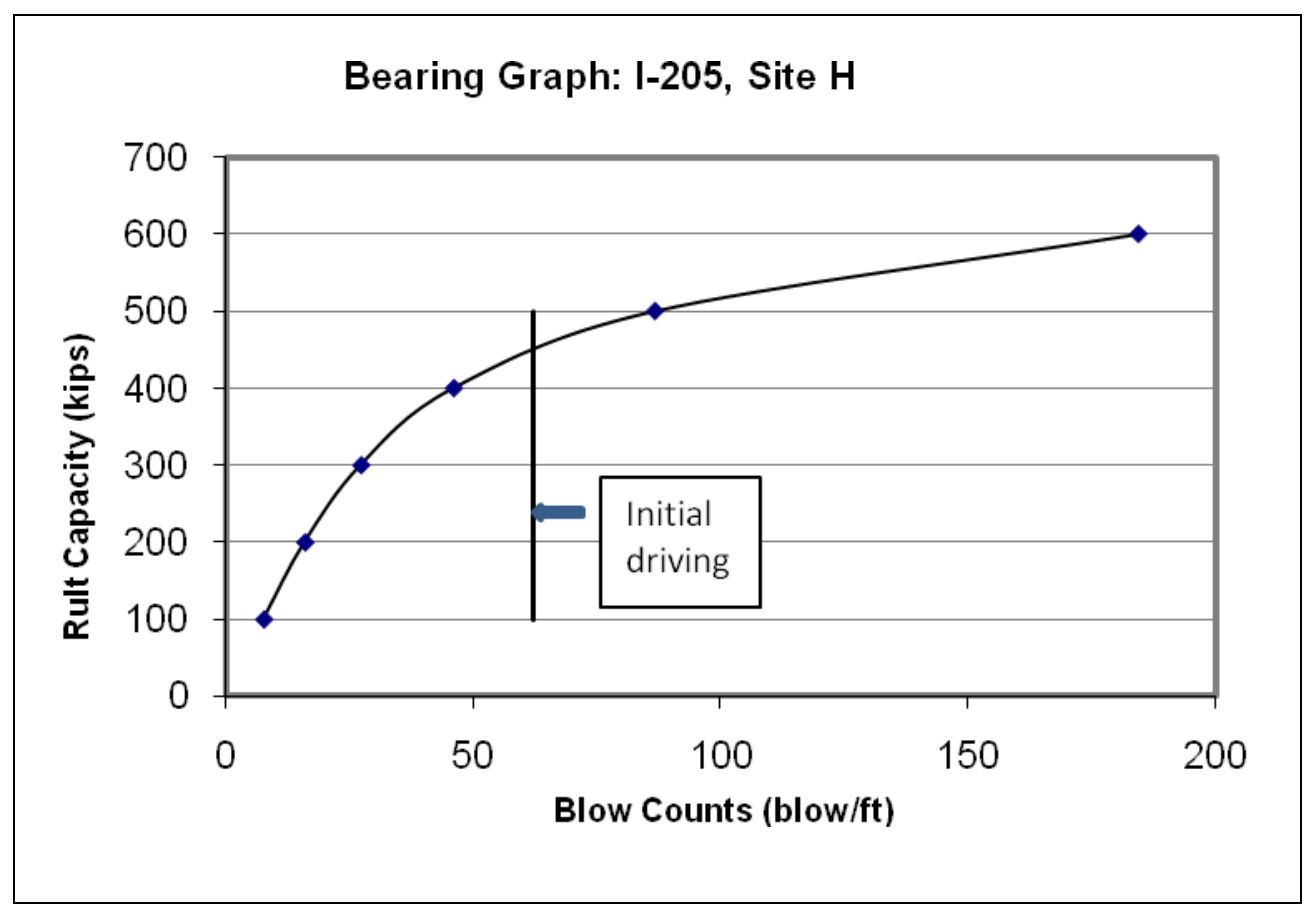

Figure 4.2: Bearing Graph I-205 Site H Pile TP-1

As shown in Figure 4.2, the GRLWEAP nominal capacity at EOID was determined from the field blow count to be 450 kips. The load test result analyzed according to Davisson's criteria, which is used by AASHTO to normalize capacity in all reliability studies, yielded a capacity of 404 kips. Note, however, that ODOT used a different pile section when the bridge was finally constructed. The design loads for the as-built section are not available for comparison to the LRFD inequality given in Equation 4-1. Therefore, no AASHTO implementation effect on the I205 Bridge can be determined, since a percent change to the number of piles to carry the LRFDfactored load cannot be determined at the bridge site. 


\subsection{AVAILABLE DATABASES}

\subsection{NCHRP 507}

Statistical confidence in any recalibration of $\varphi$ resistance factors is dependent on availability of comprehensive and complete load test databases that include EOID and BOR. The NCHRP 507 effort included assembling databases for driven piles that involved four different universities, two transportation agencies, and the author of the GRLWEAP software, GRL Engineers, Inc. of Ohio. This NCHRP 507 database, obtained by the study group by WSDOT, is called PD/LT 2000. It contains information related to 210 driven piles, many dynamically monitored during driving, with EOID blow counts, and then load tested to "failure"; some also include BOR blow counts.

Separation of the database into subgroups was documented in the NCHRP 507 report based on geographical location, soil type, pile type, driving inertia (expressed using blows for 10 centimeters), blow count time (EOID, BOR, EOR), and predicted pile static capacity. The restrike data on the 210 piles totaled 372 of the 389 data records presented. However, multiple BOR blows on the same pile were used in the statistical analysis to determine reliability of BOR nominal capacity predictions from CAPWAP. Based on the reported pile types, and using the clay, silt, and sand soil types that are most relevant to ODOT practice, the maximum number of possible data records on restrike is reduced to 133 . These include $\mathrm{H}$ piles, concrete piles, and both open and closed end pipe piles. Much of this driven pile data originated with the work of GRL Engineers, Inc.

Of special interest is the work of J. Long (2002), who accessed seven independent pile databases to identify statistical means and standard deviations for seven predicted methods to measure capacity. Some of these databases included EOID and BOR data to permit a comparison of GRLWEAP bearing graph predictions, as well as CAPWAP predictions, of capacity to the measured load test capacity. Long's work illustrated for both methods, using AASHTO reported $\varphi$ resistance factors, the improvement in predictive ability when moving from EOID to BOR to capture pile set-up-something that NCHRP 507 did not illustrate. Long reported that the improvement in both means and standard deviations when comparing EOID to BOR is, in fact, better for GRLWEAP than for CAPWAP. His work also provides the $\varphi$ resistance factor as a function of the standard deviation from each of the seven databases accessed. For highly redundant piles with a reliability index, $\beta$, of 2.33 (probability of failure 1/100), the range of $\varphi$ resistance factors ranges between approximately 0.5 and 0.6 for a DL/LL ratio of 3 and at the determined GRLWEAP standard deviation of approximately 0.4 .

FHWA has been collecting deep foundation load test information for many years, including load test results, soil boring logs, and laboratory and field tests, all for both driven and drilled deep foundations. This information, gathered by FHWA from 1985 to 2004 and containing over 100 entries, is called the Deep Foundation Load Test Database (DFLTD) and has been presented as a 
PC software program (Engineering Software Consultants undated). The DFLTD has been obtained from FHWA by the study group in preparation for a Phase 2 study. Considerable difficulty was encountered in this Phase 1 study in attempting to cross-check between PD/LT 2000 (used in NCHRP 507) and DFLTD. The amount and quality of information required for static analyses, GRLWEAP studies, and final statistical analyses are considerable and significant time and resources are required to obtain complete and full details, to reduce assumptions, and to resolve anomalies. In addition, apparent differences in notation within both databases further reduce a user's ability to cross-check. This cross-checking exercise will need to be undertaken in Phase 2.

\subsection{WSDOT ROLE AND PHASE 2 DATABASE STATUS}

After NCHRP 507 was completed, WSDOT began research to calibrate the LRFD $\varphi$ resistance factor from the Modified Gates pile driving formula, which had been in use in the state prior to LRFD implementation (Allen et al. 2005). WSDOT has been active in conducting deep foundation research, including significant efforts in driven pile capacity verification over the previous 20 years $(1988,1996$, and 2005). The primary author of these efforts, Tony Allen, is a nationally recognized expert on LRFD implementation and is available as a collaborator in guiding Phase 1 and the proposed Phase 2 of this research effort for ODOT. He serves as a valuable conduit of emerging knowledge, a resource in providing an efficient Phase 2 strategy, and a guide to understanding the limitations of NCHRP 507.

The initial efforts by WSDOT research in obtaining the NCHRP 507 database revealed organizational issues and anomalies with the documentation record (some of which are discussed above). The research group for this study has obtained from WSDOT the full working dataset compiled during its $\varphi$ resistance factor recalibration in Excel ${ }^{\circledR}$ form. The WSDOT spreadsheet included some generic EOID and BOR studies and undertook to better break down the PD/LT 2000 data entries by the introduction of quality metrics. All repeat BOR entries used in the NCHRP 507 study were removed so that only a single pile entry would be used once for EOID, and possibly again for a single "final BOR." The research group examined the revised PD/LT 2000 obtained from WSDOT and the DFLTD as the basis for the proposed Phase 2 effort, as summarized below:

- Of the 145 best quality entries in the "BOR final data" section, approximately 45 are well matched in DFLTD. An additional 18 to 20 case histories can be identified if minor anomalies can be resolved.

- In selecting suitable candidate data entries for its Modified Gates recalibration, WSDOT set an upper limit of 600 tons in capacity. Beyond this capacity, WSDOT endorses PDA signal matching with CAPWAP analysis.

- $\quad$ The WSDOT Bridge Design Manual LFRD (WSDOT 2007) endorses the Modified Gates formula used with the recalibrated $\varphi$ resistance factor for pile driving inertia blow counts in excess of 1 blow per 25 millimeters. 
- WSDOT identified energy errors on 58 pile entries in PD/LT 2000 and highlighted these entries. However, they remained in the WSDOT recalibration effort as valid datasets.

- It appears that all quakes, Q, and damping values, J, for GRLWEAP input contained in $\mathrm{PD} / \mathrm{LT} 2000$ are not default values and must be better researched and explained.

- A consistent BOR definition that matches current ODOT practice should be applied uniformly before statistical recalibration is made.

- The term "Developed" hammer energy in NCHRP 507 and PD/LT 2000 is identical to "Delivered" hammer energy in the spreadsheet supplied by WSDOT.

- It is not clear whether the long-term static capacity is with the pile behaving plugged or unplugged for WSDOT-identified BOR and EOR.

For the purpose of the recalibration effort, the demands on the case history data to perform DRIVEN and GRLWEAP, at EOID and BOR, are considerable. A thorough cross-checking of every BOR pile entry between the WSDOT spreadsheet, based on PD/LT 2000, and the DFLTD should be attempted in Phase 2. All errors and anomalies should be identified and resolved prior to a case history being included in any GRLWEAP recalibration. 


\subsection{CONCLUSIONS AND PHASE 2 RECOMMENDATIONS}

\subsection{CONCLUSIONS}

The ODOT Bridge Section has a demonstrated record of satisfactory ASD performance for driven pile foundations. This historical record can be used to offer supporting evidence that ODOT's probability of failure is less than the $1 / 100$ probability for redundant piles used in NCHRP 507. NCHRP 507 set this probability to establish a Target Reliability Index at 2.33 in deriving $\varphi$ resistance factor values. This record of satisfactory performance suggests that current ODOT practice has achieved desirable lower probabilities of failures from past ASD practice set by pre-LRFD AASHTO codes. Section 2 illustrated a direct calibration from ASD for the LRFD Strength I category, which resulted in $\varphi$ resistance factor at 0.55 for an ASD factor of safety of 2.5 without considering bias. Higher $\varphi$ resistance factor values are found if the GRLWEAP bias reported in NCHRP 507 is included, and also if higher DL/LL ratios are used. The survey of Northwest state DOTs reported in Chapter 3 revealed that 80 percent of the DOTs believe the AASHTO sanctioned $\varphi$ resistance factor for GRLWEAP of 0.4 is conservative and 37.5 percent do not use it.

The case history examination of the friction piles at the Corvallis Bypass Bridge site provided insight into a comparison between ODOT practice, with the nominal capacities from GRLWEAP and CAPWAP, and the current LRFD based AASHTO code requirements. The examination showed that strict interpretation of the requirements at EOID would have required more than double the number of piles that were actually driven at Bent 3. Thus, with Northwest state DOTs reporting proposed construction of approximately 750 new bridges in the next 10 years, implementation of LRFD will likely increase foundation costs considerably.

The Corvallis Bypass Bridge study revealed that ODOT's current practice of moving to the BOR application of GRLWEAP for piles with likely set-up and setting appropriate geotechnical parameters would have required 38 percent more piles at Bent 3 if the current AASHTO $\varphi$ resistance factor of 0.4 was applied. In part, this percent change is due to the acceptance of a lower factor of safety in ASD approved by both ODOT and FHWA, which lowered the number of piles required in construction. However, the CAPWAP analyses of the test pile at Bent 3 reported the nominal capacity and confirmed that the as-built foundation does satisfy (almost exactly) the AASHTO code requirements. When applied to this Bent study site to establish the appropriate GRLWEAP $\varphi$ resistance factor at BOR, as required to yield the current AASHTO minimum number of piles, the $\varphi$ resistance factor increases to 0.55 .

The ASD calibration, Northwest practice, and the ODOT case study support the preliminary increase of the GRLWEAP BOR $\varphi$ resistance factor to a range of 0.5 to 0.55 . The work by J. Long (2002) provides independent confirmation that continuing this research from Phase 1 to Phase 2 is worthwhile, with the objective of raising the AASHTO-reported GRLWEAP $\varphi$ 
resistance factor higher than the present 0.4 . While a recalibration of BOR is conducted, a $\varphi$ resistance factor of 0.5 at EOID is recommended.

\subsection{PHASE 2 TASKS}

ODOT and the Phase 1 study group were fortunate in obtaining the NCHRP 507 database and its modifications, including quality metrics and pile selection strategy from WSDOT. This study has identified that approximately 30 percent of the highest quality BOR case histories in the DFLTD database have complete geotechnical data. Based on surveys, personal communication with other researchers, and recent publications, it is expected that between 10 and 30 additional case histories containing EOID and BOR data could be available. Considerable effort should be made in Phase 2 to resolve anomalies in the modified PD/LT 2000 database from NCHRP 507 supplied by WSDOT, to obtain missing subsurface information, and to locate additional case histories.

The ODOT Research program group can contribute to Phase 2 by gaining the assistance of other DOTs in data gathering for the proposed Phase 2 database effort. The move to using BOR data to better include pile set-up for GRLWEAP can now exploit new versions of the software released in 2005 that include set-up and relaxation features not present in the earlier versions used by Paikowsky et al. (2004) and in the WSDOT effort (2007)

The following tasks are anticipated in Phase 2:

1. Form a Technical Advisory Committee (TAC), which should include a role for WSDOT and for Robert Miner Dynamic Testing Inc. of Seattle, to reach agreement on the detailed recalibration strategy to meet ODOT's needs. Any emerging implementation progress by other DOTs working with GRLWEAP and BOR should be identified and evaluated.

2. Attempt to identify any predominant soil groups for future bridge sites in Oregon. Compile a set of data quality matrix and quality needs to evaluate all friction pile candidate EOID and/or BOR matched case histories that are similar to ODOT practice, including pile type, pile length, soil side and tip conditions, etc., for any subsets.

3. Continue to build the research support literature base. The ODOT Research group should vigorously pursue building key contacts and securing close collaboration with those state DOT partners engaged in EOID and/or BOR recalibration of $\varphi$ resistance factors, as well as securing any new pile load test details.

4. Establish, document, and reach TAC agreement on the definition(s) of BOR to be used in the Phase 2 study. Reach agreement on a strategy for using CAPWAP results, if available, to refine quake, damping, and hammer performance.

5. Merge the DFLTD database and the PDLT 2000 supplied in the WSDOT spreadsheet in a new customized format.

6. Rank all case histories and identify missing information and anomalies. Resolve these issues by phone, e-mail, or published report studies. Establish statistical significance 
parameters for the number of case histories required in any possible subsets, based on soil type, pile length, and driving resistance. Modify and reconstruct the WSDOT spreadsheet to form a complete DRIVEN plus GRLWEAP activity archive.

7. Conduct both an EOID and a new BOR statistical analysis of datasets in the revised database discussed in task 5. Present and evaluate the histograms, compare them to NCHPR 507, and derive $\varphi$ resistance factors for a reliability index $\beta$ of 2.3 for redundant piles.

8. In final reporting and implementation, include standard of practice language for relevant ODOT manuals relating to GRLWEAP applications and use, including guidance for any outsourced professional services.

It is expected that these activities would be accomplished in 2 to 3 years depending on the level of resources available. 


\section{REFERENCES}

American Association of State Highway and Transportation Officials (AASHTO). LRFD Bridge Design Specifications. American Association of State Highway and Transportation Officials, Third Edition. Washington, DC. 2004.

American Association of State Highway and Transportation Officials (AASHTO). LRFD Bridge Design Specifications. American Association of State Highway and Transportation Officials, Fourth Edition. Washington, DC. 2007.

T. Allen. Development of Geotechnical Resistance Factors and Downdrag Load Factors for LRFD Foundation Strength Limit State Design. Report No. FHWA-NHI-05-052, Federal Highway Administration (FHWA). Washington, DC. 2005 a.

T.M. Allen. "Development of the WSDOT Pile Driving Formula and its Calibration for Load and Resistance Factor Design (LRFD)." WA-RD 610.1, Washington State Transportation Center (TRAC). Seattle, Washington. 2005 b.

T. Allen, A. Nowak, and R. Bathhurst. "Calibration to Determine Load and Resistance Factors for Geotechnical and Structural Design.” Transportation Research Board, Circular E-C079. September 2005.

CH2M Hill. "Foundation Load Test, I-205 Columbia River Bridge." Report to ODOT Bridge Division, Portland, Oregon. 1974.

J. DiMaggio, T. Saad, T. Allen, B.R. Christopher, A. Dimillo, G. Goble, P. Passe, T. Shike, and G. Person. Geotechnical Engineering Practices in Canada and Europe. Report No. FHWA-PL99-013, Federal Highway Administration. March 1999.

J.M. Duncan. "Factors of Safety and Reliability in Geotechnical Engineering." Journal of Geotechnical and GeoEnvironmental Engineering, American Society of Civil Engineers (ASCE), Vol. 126, No. 4: 307-316. 2000.

Engineering Software Consultants. "Deep Foundation Load Test Database (DFLTD) User Manual." Federal Highway Administration, Turner-Fairbank Highway Research Center. McLean, Virginia. Undated.

P.J. Hannigan, G.G. Goble, G.E. Likins, and F. Rausche. Design and Construction of Driven Pile Foundations. Report No. FHWA-NHI-05-042 and FHWA-NHI-05-043, Federal Highway Administration. Washington, DC. April 2006.

B.R, Jackson. “LRFD: Case Studies for ODOT Bridge Pile Foundations.” MS Project Report, Portland State University. Portland, Oregon. 2008. 
A. Lacombe et al. "USDOT 2005, Research, Development and Technology (RD\&T) Plan," Sixth Edition. October 2004.

J. Long. "Resistance Factors for Driven Piling Developed from Load Test Databases." Proceedings of Deep Foundations Congress. American Society of Civil Engineers (ASCE). Orlando, Florida. 2002.

D. Mathias and M. Cribbs. DRIVEN 1.0: A Microsoft Windows ${ }^{\mathrm{TM}}$ Based Program for Determining Ultimate Vertical Static Pile Capacity. Report No. FHWA-SA-98-074, Federal Highway Administration. Washington DC. 1998.

Oregon Department of Transportation ODOT). "Bridge Log." Bridge Engineering Section, Bridge Operations Unit, Salem, Oregon. 2007.

S. G. Paikowsky, C. Kuo, G. Baecher, B. Ayyub, K. Stenersen, K. O’Malley, L. Chernauskas, and M. O'Neill. "Load and Resistance Factor Design (LRFD) for Deep Foundations." NCHRP Report 507, Transportation Research Board. Washington, DC. 2004.

Pile Dynamics Inc. and GRL Engineers, Inc. "Wave Equation Analysis of Pile Driving (GRLWEAP).” Cleveland, Ohio. 2005.

F. Rausche, G. Thendean, H. Abou-mator, G.E. Likins, and G.G. Goble. Determination of Pile Driveability and Capacity from Penetration Tests. Report No. FHWA-RD-96-181, Federal Highway Administration. May 1997.

R. Salgado. The Engineering of Foundations. McGraw-Hill, Inc. 2006.

Washington State Department of Transportation (WSDOT). Bridge Design Manual LRFD. 2007. 


\section{APPENDIX A}

FHWA NORTHWEST GEOTECHNICAL WORKSHOP SURVEY SEPTEMBER 2007 



\author{
WESTERN FEDERAL LANDS HIGHWAY \\ DIVISION 610 EAST FIFTH STREET \\ VANCOUVER, WA 98661-3801
}

Technical Memorandum 07- 01

Subject: INFORMATION: Load Resistance Factor (LRFD)

Date: September 24, 2007
Wave Equation Resistance Factor
Research Survey
Geotechnical/ Technical Services
WFLHD Geotechnical
Senior Geotechnical Engineer
WFLHD Geotechnical Team Lead

From: Diann Morehouse,

To: $\quad$ Rich Barrows, P.E.

Transmitted herewith are the results of the Load Resistance Factor (LRFD), Wave Equation Resistance Factor Research Survey. The Oregon Department of Transportation and Portland State University, in collaboration with Federal Highway Administration and Washington State Department of Transportation collected information pertaining specifically to pile driving acceptance criteria from participating state DOT's. The desired information includes assessing the overall use of the wave equation in DOT practice and the need and support of recalibration of the driven pile resistance factor, $\varphi$, specified for use with GRL-WEAP.

The survey consisted of 15 questions that were designed to extrapolate the methods performed by the participating DOT's for driven pile designs. The survey was sent to the Steering Committee members of the Northwest Geotechnical Workshop, August 8, 2007 by an email form. The respondents were asked to return the completed survey by email no later than August 27, 2007. Survey questions and responses were compiled into a PowerPoint presentation and the results presented at the Northwest Geotechnical Workshop September 5, 2007 in Coeur d'Alene, Idaho. The presentation was part of a group discussion among the Steering Committee members as well as other representatives within the participating DOT's at the conference. In addition, the survey and results were discussed at FHWA National Geotechnical Conference in Boise, Idaho, September 18, 2007.

The results of the Wave Equation Resistance Factor Research Survey are presented in the Appendix A. Comments from the survey are listed anonymously in Appendix B. Comments made in the group discussion are listed in Appendix C.

Cc: Dr. Trevor Smith, P.E., Portland State University

Geotechnical Technical Memorandum File 


\section{APPENDIX A \\ SURVEY RESULTS}

1. Is your agency currently designing driven pile foundations using the LRFD code?

$\begin{array}{lc}\text { Response } & \text { Response } \\ \text { Percent } & \text { Count }\end{array}$

Yes

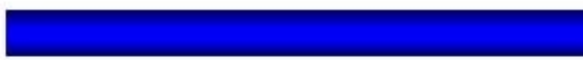

$78 \%$

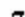

7

No Reionses to Question

$22 \%$

2

No

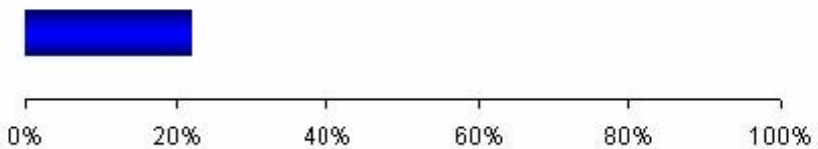

2. Provide the approximate percentage of use of each given method for determining final pile driving criteria for all pile driving projects in your state.

$\begin{array}{cccc}\begin{array}{c}\text { Response } \\ \text { Percent }\end{array} & \begin{array}{c}\text { Response } \\ \text { Count }\end{array} & \begin{array}{c}\text { No Responses to } \\ \text { Question }\end{array} & 0 \\ 39 \% & 3 & 6 & \\ 25 \% & 8 & \begin{array}{c}\text { One Response to } \\ \text { Question }\end{array} & \text { I } \\ 8 \% & 2 & \begin{array}{c}\text { Two Responses } \\ \text { to Question }\end{array} \\ 0 \% & 1 & \begin{array}{c}\text { Three Responses } \\ \text { to Question }\end{array} \\ 2.5 \% & 1 & \begin{array}{c}\text { Four Responses } \\ \text { to Question }\end{array}\end{array}$

Dynamic formula

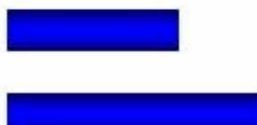

Wave Equation only

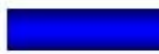

equation

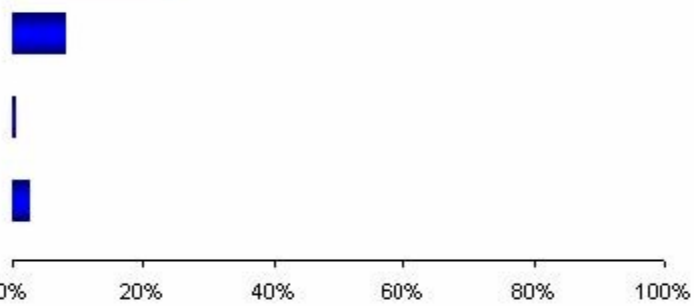

PDA/CAPWAP no wave equation

Load test, PDA/CAPWAP with or

without wave equation

to Question

3. Indicate the degree to which your agency uses the wave equation analysis program (WEAP) (select all answers that apply)?

Never

For establishing final pile driving criteria during installation

For Pile Driveability studies during design

For Hammer Approval

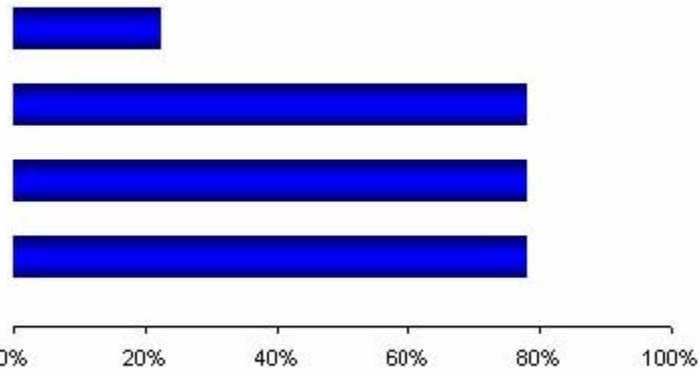

\begin{tabular}{|c|c|c|}
\hline $\begin{array}{c}\text { Response } \\
\text { Percent }\end{array}$ & $\begin{array}{c}\text { Response } \\
\text { Count }\end{array}$ & \\
\hline $22 \%$ & 2 & $\begin{array}{c}\text { No Response to } \\
\text { Question }\end{array}$ \\
\hline $78 \%$ & 7 & \\
\hline $78 \%$ & 7 & $\begin{array}{c}\text { One Response to } \\
\text { Question }\end{array}$ \\
\hline \multirow[t]{3}{*}{$78 \%$} & 7 & \\
\hline & & $\begin{array}{c}\text { Two Responses } \\
\text { to Question }\end{array}$ \\
\hline & & $\begin{array}{c}\text { Three Responses } \\
\text { to Question }\end{array}$ \\
\hline
\end{tabular}




\section{APPENDIX A}

\section{CONTINUED}

4. If you use WEAP for extablishing final pile driving criteria. please identify which types of projects it would be specified on: (select all answers that apply).

May be used on any project

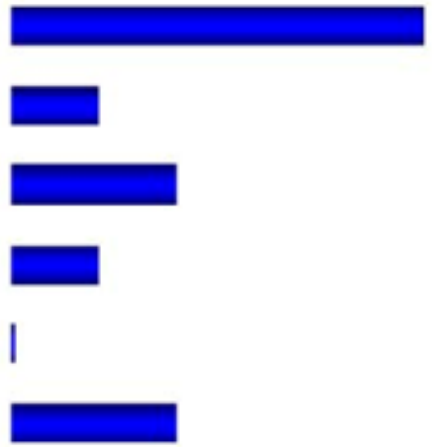

Only used an larger, more complex projects

Primarly wed for hieh eapaeity piles or high driving stress

conditions

Only used if PDA is condurted (for more accurate delivered energy values)

Only used if PDA with signal matkhing (c.g, CAPWAP) is conducted

Only used an selected projects
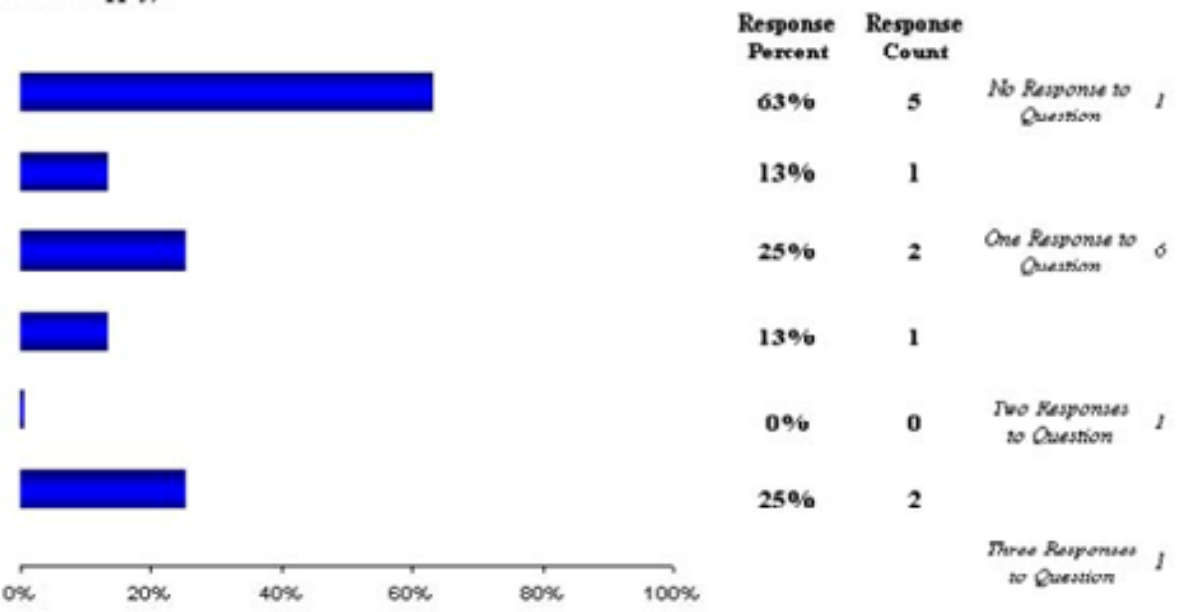

5. If you do not use the wave equation program, please select the answer below that best fits your reasoning:
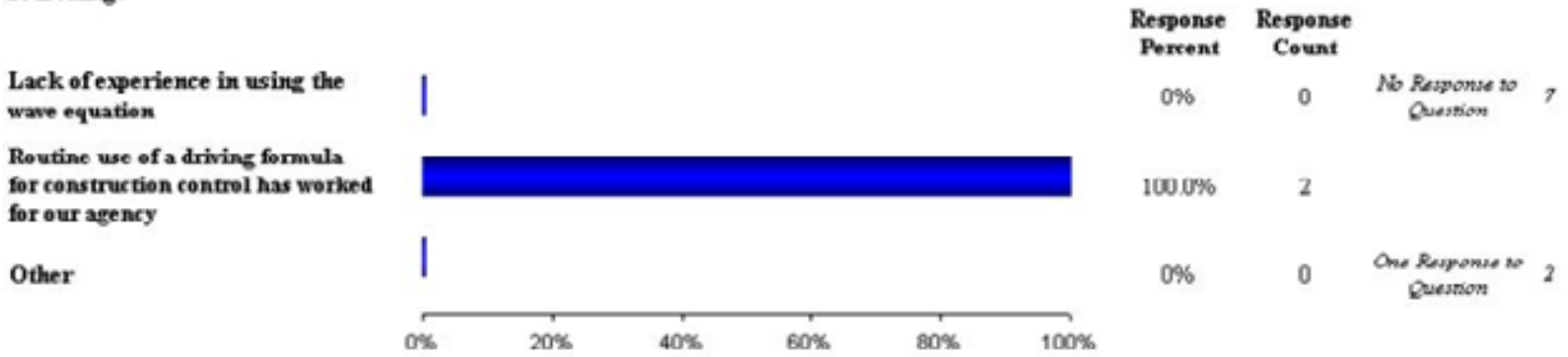

6. Are driving criteria from WEAP determined in your organization at:

End of Driving (EOD)

Beginuing of Restrike (BOR)

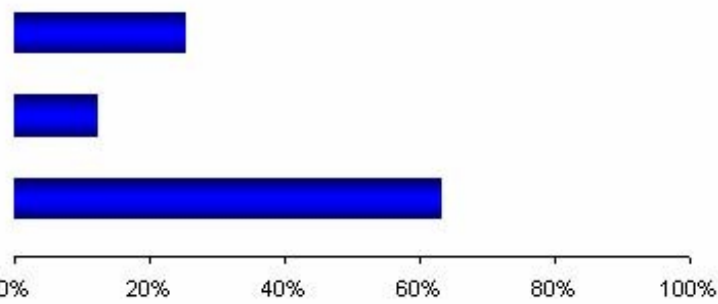

Both

$\begin{array}{ccc}\begin{array}{c}\text { Response } \\ \text { PeIcent }\end{array} & \begin{array}{c}\text { Response } \\ \text { Count }\end{array} & \\ 250 \% & 2 & \begin{array}{c}\text { Mo Response to I } \\ \text { Question }\end{array} \\ 12 \% & 1 & \\ 630 \% & 5 & \begin{array}{c}\text { One Response to } \\ \text { Question }\end{array}\end{array}$




\section{APPENDIX A}

\section{CONTINUED}

7. How long do you typically wait after EOD to conduct a restrike test?

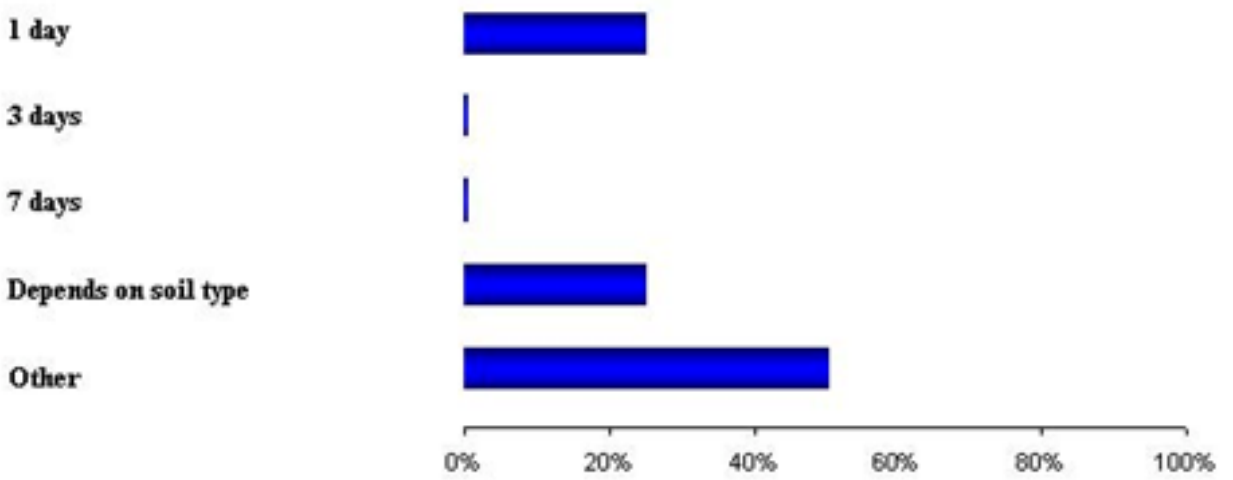

\begin{tabular}{|c|c|c|}
\hline $\begin{array}{c}\text { Response } \\
\text { Percent }\end{array}$ & $\begin{array}{c}\text { Response } \\
\text { Count }\end{array}$ & \\
\hline $25.0 \%$ & 2 & $\begin{array}{c}\text { No Response to } \\
\text { Question }\end{array}$ \\
\hline $0 \%$ & 0 & \\
\hline $0 \%$ & 0 & $\begin{array}{c}\text { Ore Response to } \\
\text { Question }\end{array}$ \\
\hline $25.0 \%$ & 2 & \\
\hline $50.0 \%$ & 4 & $\begin{array}{l}\text { Two Responies } \\
\text { to Question }\end{array}$ \\
\hline
\end{tabular}

8. How do you determine the BOR driving resistance (blow count in blows per inch)?

Nuabex of blows for first iscli of pile set

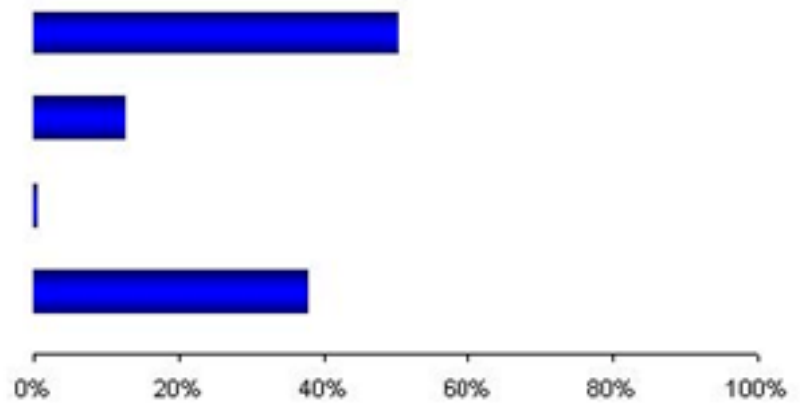

Inverse of pile set for first 10

blows

Other

9.Please identify the resistance fachor used by your agency when final driving criteria are developed using only the wave equation analysis program (PDA, CAPWAP and/or load test data are not available).

\section{A0, per the AASHTO LRFD specifications}

0.55, based on local experience 0.G5, based un lucal experiente

Based on calibration to load test database applicable to your agency is typical local geologic conditions

None of the answers provided

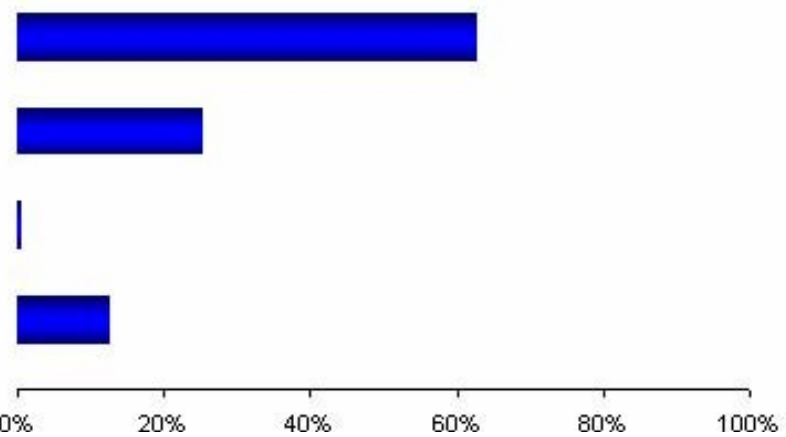

Response Percent

$625 \%$

$250 \%$

$0 \%$

$125 \%$
Response

Count

$\begin{array}{cc}5 & \text { No Response to I } \\ \text { Question } & \\ 2 & \text { One Response to } \\ \text { Question } & 8\end{array}$

1 


\section{APPENDIX A \\ CONTINUED}

10. Does your agency consider the current AASHTO resistance factor of 0.40 for WEAP to be:
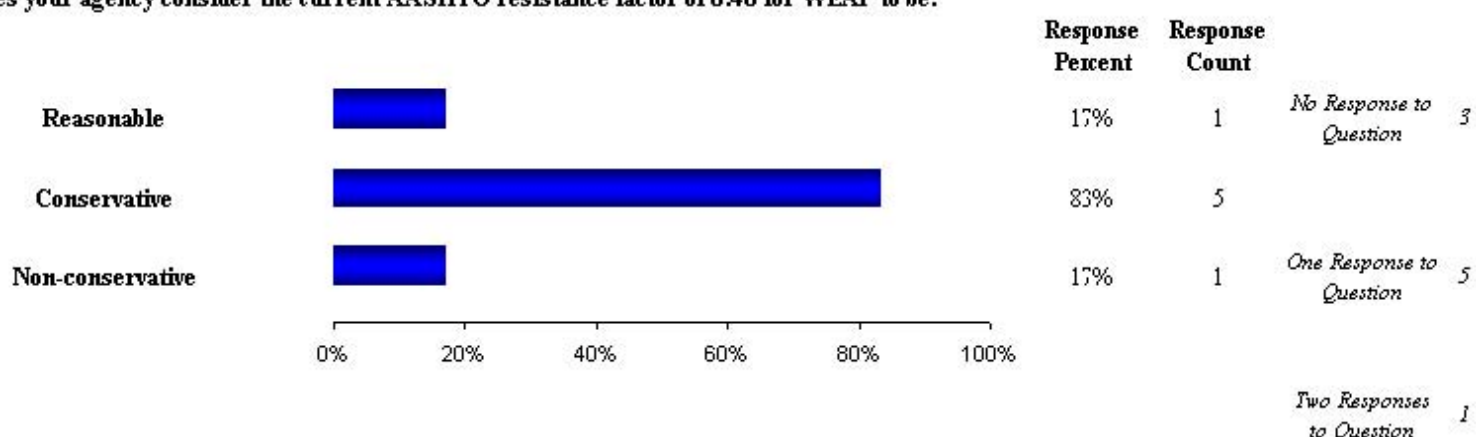

11. Is your agency presently engaged in a current effort to revise the resistance factor used with WEAP for driven piles that better accomumodates your local/regional practice?
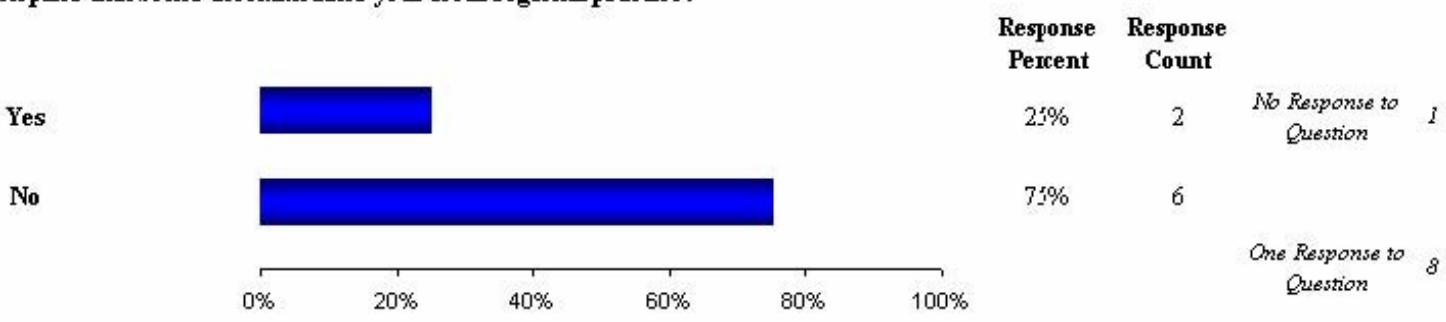

12. Please provide the approximate number of any well-documented full scale axial compression pile load tests on driven piles, completed within the last 10 years and performed under the direction of your agency. Please indicate if BOR data is available for these load tests and if the data has been previously supplied to the FHWA load test data base (if known).

$\begin{array}{cccc}\begin{array}{c}\text { Response } \\ \text { Percent }\end{array} & \begin{array}{c}\text { Response } \\ \text { Count }\end{array} & & \\ 11 \% & 1 & \begin{array}{c}\text { No Response to } \\ \text { Question }\end{array} & 0 \\ 2 \% \% & 2 & & \\ 6 \% \% & 6 & \begin{array}{c}\text { One Response to } \\ \text { Question }\end{array} & 9\end{array}$

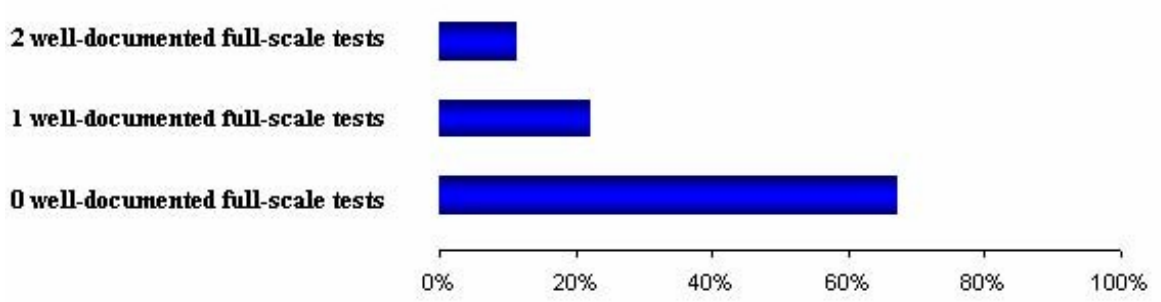

BOR available? -- Only two states had data available

Supplied to FHWA Load Test Database? -- Two states identified that their data has been supplied to FHWA load test data base 


\section{APPENDIX A \\ CONTINUED}

13. Approximately, how many driven pile supported bridges is in your agency likely to design under LRFD code over the next 5 years and the next 10 years (including consultant designed bridges).

$\begin{array}{cccccccc}\text { Survey No. } & 1 & 2 & 3 & 4 & 5 & 6 & 7 \\ \text { Next 5 years } & 50 & 90 & 50 & 5 & 50 & 25 & 120 \\ \text { Next 10 years } & 100 & 170 & 100 & 10 & 100 & 50 & 220\end{array}$

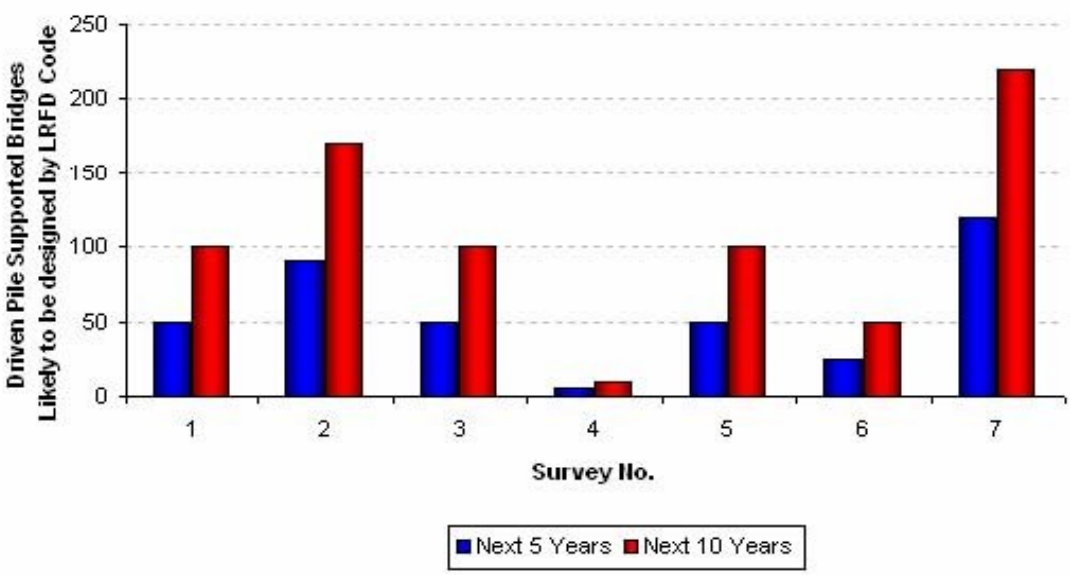

No Response to Question

One Response to Question

14. Are you (or someone from your agency) willing to contribute advice and serve on a TAG for and effort to review the WEAP resistance factor?
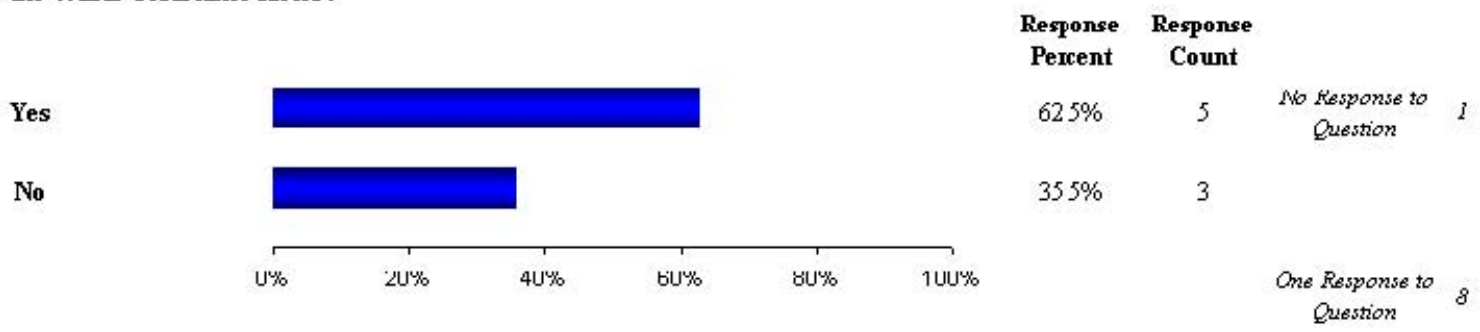

15. Is your agency willing to contribute to a pooled fund effort to review and recalibrate the WEAP

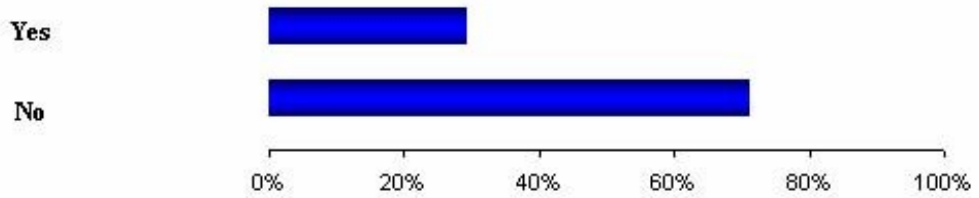

$\begin{array}{cccc}\begin{array}{c}\text { Response } \\ \text { Percent }\end{array} & \begin{array}{c}\text { Response } \\ \text { Count }\end{array} & \\ 20 \% & 2 & \begin{array}{c}\text { No Response to } \\ \text { Question }\end{array} & \\ 71 \% & 5 & \\ & & \begin{array}{c}\text { One Response to } \\ \text { Question }\end{array} & 7\end{array}$




\section{APPENDIX B \\ Comments on Survey}

1. Is your agency currently designing driven pile foundations using the LRFD code?

- $\quad$ No -We plan to use the LRFD code for projects starting preconstruction after Oct 1 , $\underline{2007 .}$

- $\quad$ No - We haven't done substructure design yet, but we are very close to being able to do so.

- $\quad$ Yes -We provide an Ultimate skin friction and our Bridge Program actually designs the foundation

- Yes -Our design practice consists of two scenarios. The majority of our sites involve end-bearing piles on bedrock driven to refusal, while we have a few cases of longer friction piles. Where friction piles are used, we use the static analysis methods and WEAP to establish driving criteria, and then use the PDA for quality control. For end bearing piles, the practice is based on calibrating to an allowable capacity of $0.25 \mathrm{Fy}$. We are starting a small research project to determine the potential of increasing the capacity on end bearing piles using the structural capacity per AASHTO LRFD.

- $\quad$ Yes - - ust begun full implementation early this year

2. Provide the approximate percentage of use of each given method for determining final pile driving criteria for all pile driving projects in your state.

- We use the Gates Formula as a check on the PDA and Wave Equation on some projects.

- We have a modified ENR formula that we use for field verification.

- $\quad$ Only two load tests were performed in the last 25 years.

- $\quad$ Existing CDOT specification which uses virtual refusal criteria established based on local experience. PDA involvement in projects is increasing as potential for cost savings is realized by project engineers

3. Indicate the degree to which your agency uses the wave equation analysis program (WEAP) (select all answers that apply).

- Hammer Driveability and Never - On sites with shallow bedrock and end bearing conditions WEAP is not used, while on sites with friction piles WEAP will be used for driveability analysis 
4. If you use WEAP for establishing final pile driving criteria, please identify which types of projects it would be specified on: (select all answers that apply)

- $\quad$ May be used on any project $-\underline{\text { All projects }}$

- $\quad$ No Response - We don't use WEAP

- May be used on any project - We use on every pile Driving job.

- May be used on any project - WEAP is used for all projects with driven pile foundations since 1980 .

- On Selected Projects - Used on sites with longer friction piles.

- May be used on any project and primarily used for high capacity... Always used when PDA/CAPWAP methods are employed to establish drivign criteria for the remaining produciton piles (the ones not PDA tested)

- Only on Selected Projects -We typically use only WEAP (w/out PDA and CAPWAP) on remote jobs where piles are being driven to bedrock.

5. If you do not use wave equation program, please select the answer below that best fits your reasoning.

- $\quad$ Routine Use - This would apply in situations where WEAP is not used

6. Are driving criteria from WEAP determined in your organization at:

- $\quad$ End of Driving $-90 \%$ of the time we reach desired capacity at EOD. So we don't perform a lot of restrikes.

7. How long do you typically wait after EOD to conduct a restrike test?

- Depends - $\quad$ We would typically wait a week, but could go mlonger in clayey soils

- Other -Depends on soil type, required increase in capacity, and Contractor's schedule.

- Other - Typically several days later, though have done within 1-2 days.

- No Response - Don't use WEAP

- Other $-\underline{\text { We conduct very few restrikes. }}$

○ $\quad 0.40$-As per our Bridge Program.

- Depends - Waiting time is determined for each project, based on foundation soil types. It could vary from 1 or 2 days for cohesionless soils to 7 days for cohesive 
soils. Waiting time longer than 7 days is sometimes specified if construction schedule permits. 1 day and Depends - We
to construction schedules.

\section{How do you determine the BOR driving resistance (blow count in blows per inch)}

- Other -We have no set policy here, but would probably drive at least an inch or two

- Other -Either blows per inch or foot

$\circ \quad$ No Response - Don't use WEAP

- Other -Number of blow per foot for pile driven in soil and blow per inch for pile driven into bedrock

- Inverse of pile set in the first 5 blows - by recording and evaluating the set for the first 5 hammer blows, then the next 5 blows and then the next 5 blows ( 15 blows total) to see if the resistance is decreasing with increase in number of blows (back to undrained conditions). Typically the blow count would be the inverse of the setper first 5 blows.

- Number of blows for the first inch -We typically don't set a BOR driving criteria. We do a BOR PDA/CAPWAP and use EOID criteria for that pile if capacities are met during restrike test.

9. Please identify the resistance factor used by your agency when final driving criteria are developed using only the wave equation analysis program (PDA, CAPWAP and/or load test data are not available).

- $\quad$ None -

- No Response - Don't use WEAP

- $\quad \mathbf{0 . 4 0}$-We have not based a design on WEAP since we started designing (several years ago) with LRFD. 
10. Does your agency consider the current AASHTO resistance factor of 0.40 for WEAP to be Conservative, Non-conservative, or Reasonable?

- No Response - We have not designed enough

- Conservative -Current AASHTO 0.40 resistance factor roughly relates to a factor of safety of 3.5 . We used to use 2.5 with WEAP only.

- $\quad$ Reasonable - However, we feel the Energy Equation resitance factor should not be equal to WEAP.

11. Is your agency presently engaged in a current effort to revise the resistance factor used with WEAP for driven piles that better accommodates your local/ regional practice?

- Yes - $\quad$ ODOT study

- $\quad$ No response - All pile supported bridges are designed using LRFD. But probably only 10 to $20 \%$ of our bridges are designed using piles. Shafts are much more common.

- Yes -Jan Six, Oregon DOT (503-986-3377) and Trevor Smith ,Portland State Univ. (503-725-3225). Currently conducting Phase I effort which includes gathering and evaluating pile load test database information to re-evaluate WEAP phi factor based on BOR data. Phase II if funded would consist of performing the recalibration work.

12. Please provide the approximate number of any well-documented full scale axial compression pile load test on driven piles, completed within the last 10 years and performed under the direction of your agency. Please indicate if BOR data is available for these load tests and if the data has been previously supplied to the FHWA load test database (if known).

- One test - Don't know

- $\quad 0$ tests - Not sure how many. Only a few.

- $\quad$ No Response - Have not done any pile load tests in the last 10 years (however in question 13, reports that in 5 years will design 50 bridges and 10 years 100).

- $\quad$ No Response -Several load tests have been performed on D/B jobs. We don't have ready access to this data but we recommend contacting Dr. Kyle Rollins of BYU who has performed several load tests (801.422.6334).

13. Approximately, how many driven pile supported bridges is in your agency likely to design under LRFD code over the next 5 years and the next 10 years (including consultant designed bridges).

- $\quad$ 25, $\mathbf{5 0}$ - Assuming 5 per year

120, 220 - This is a very rough estimate 
14. Are you (or someone from your agency) willing to contribute advice and serve on a TAG to review the WEAP resistance factor?

- Yes -Already doing so

- No response -maybe in the future after we use LRFD awhile

○ $\quad$ No -Don't use WEAP

- $\quad$ No -We have limited personnel resources for this at our present staffing levels.

15. Is your agency willing to contribute to a pooled fund effort to review and recalibrate the WEAP resistance factor?

- No response - We have no additional funding available right now.

- $\quad$ No -FHWA likely already has funded work in this area. We would not duplicate our contribution to this effort, but can support with team participation

- $\quad$ No -Don't use WEAP

- No Response -

- No - At this time, our efforts on pile research is directed towards improving the resistance factor towards end bearing piles on sedimentary bedrocks in the Front $\underline{\text { Range urban area of Colorado }}$

- $\quad$ Yes -If we can get it prioritized, we'd be willing to contribute. 



\section{Appendix C \\ Discussion in Group Discussion}

- Jan Six and Bob Kimberling co-presented the results of the LRFD survey.

- For the transition between the results and the group discussion, Jan Six discussed Oregon's use of LRFD reduction factor on pile designs. However, based on local soil parameters the designs are equating a factor of safety of 3.5 .

- Jan Six brought to the attention of the workshop that the report NCHRP 507 was the foundation for the LRDF resistance factor, $\varphi$, of 0.40 and that the study in NCHRP 507 may not been as thorough as possible.

- Jan Six discussed the joint work with ODOT, Portland State University, and Oregon Transportation Research and Education Consortium (OTREC). The objectives of Phase 1 of the research was to determine concerns the States in the northwest, may have to the reduction factor. Jan Six continued by trying to determine the interest from other States to pool resources with Oregon Transportation Research and Education Consortium (OTREC) stating that support from other DOT would help fund phase 2, which would verify the resistance factors determined in NCHRP 507 . The audience did not provide any positive feedback for funding.

- The group discussion began by a question to the discussion leaders whether the objective was to revise the resistance factor, $\varphi$, for driven piles. The answer was that they would like to recalibrate the equation by using site-specific soil and restrike data.

- A comment came up that program, Legacy, is having problems with LRFD when calculating MSE walls with seismic parameters.

- A question was asked of what kind of experiences do the DOTs have with CAPWAP.

- Can the wave equation be calibrated from CAPWAP results?

- Calibrating wave equation with CAPWAP is not well documented and so maybe we need a TRB Circular discussing this concept.

- Colorado is has allotted funds to look at the reduction factors for end bearing piles in sedimentary rock. 
P.O. Box 751

Portland, OR 97207

www.otrec.us

OTREC is dedicated to stimulating and conducting collaborative multi-disciplinary research on multi-modal surface transportation issues, educating a diverse array of current practitioners and future leaders in the transportation field, and encouraging implementation of relevant research results. 